\title{
O Comportamento dos Componentes da Volatilidade das Ações no Brasil
}

(The Behaviour of Volatility Components of Brazilian Stocks)

\author{
Hudson Chaves Costa* \\ João Henrique Gonçalves Mazzeu** \\ Newton Carneiro Affonso da Costa Jr.**
}

\begin{abstract}
Resumo
O presente trabalho avalia através da abordagem de Campbell et al. (2001) a evolução de três componentes da volatilidade das ações brasileiras no período entre 1996 e 2010. É identificado que o componente idiossincrático da volatilidade não apresenta a mesma tendência de crescimento temporal verificada em outros países. Ao contrário, exibe tendência de queda a partir do final da década de 90. Testes estatísticos são realizados para confirmar essa hipótese, incluindo testes de quebra estrutural, raiz unitária e de tendência. Os resultados indicam que a volatilidade idiossincrática possui quebra estrutural e não há evidências de que a tendência é estocástica, pois ao realizar testes de tendência determinística verifica-se que há um padrão de queda estatisticamente significativo.
\end{abstract}

Palavras Chave: Volatilidade idiossincrática; Correlação média; Volatilidade desagregada; Mercado brasileiro de ações.

JEL Codes: G11, G12.

Submetido em 21 de setembro de 2015. Reformulado em 21 de junho de 2016. Aceito em 21 de junho de 2016. Publicado on-line em 27 de junho de 2016. O artigo foi avaliado segundo o processo de duplo anonimato além de ser avaliado pelo editor. Editor responsável: Márcio Poletti Laurini.

* Programa de Pós-Graduação em Economia, Universidade Federal do Rio Grande do Sul (UFRGS): Email: hudsonchavs@gmail.com.

*** Departamento de Estatística, Universidad Carlos III de Madrid E-mail: joao.hgm@uol.com.br.

**** Departamento de Economia, Universidade Federal de Santa Catarina (UFSC). Email: ncacjr@gmail.com.

Rev. Bras. Finanças (Online), Rio de Janeiro, Vol. 14, No. 2, June 2016, pp. 225-268 ISSN 1679-0731, ISSN online 1984-5146

(C)2016 Sociedade Brasileira de Finanças, under a Creative Commons Attribution 3.0 license http://creativecommons.org/licenses/by/3.0 


\begin{abstract}
The present paper evaluates by approach of Campbell et al. (2001) the evolution of the three volatility components of the Brazilian stocks in the period 1996 to 2010. It is identified that the idiosyncratic component of the volatility does not have the same temporal growth trend in other countries. Instead, it displays a downward trend from the end of the 90's. Statistical tests were performed to confirm this hypothesis, including structural break test, unit root and trend. The results indicate that the idiosyncratic volatility has structural break and there is no evidence that the trend is stochastic, because when performing deterministic trend tests it appears that there is a statistically significant decrease pattern.
\end{abstract}

Keywords: Idiosyncratic volatility; Average correlation; Disaggregated volatility; Brazilian stock Market.

\title{
1. Introdução
}

Pesquisar e analisar o comportamento dos preços dos ativos financeiros permanece um anseio em diversos estudos. A pioneira análise de Markowitz (1952) desencadeou uma linha de pensamento que propunha a mensuração do risco de ativos a partir do retorno esperado e sua variância. Porém, a difícil aplicabilidade inerente ao cálculo das covariâncias entre os ativos individuais motivou Sharpe (1964), Lintner (1965) e Mossin (1966) a desenvolverem o Capital Asset Pricing Model (CAPM) que relaciona o retorno esperado de um ativo ao seu risco nãodiversificável e ao retorno do ativo livre de risco, enquanto o risco idiossincrático é tratado no CAPM como aquele que pode ser diversificado.

Não obstante, a não verificação empírica do CAPM (Basu, 1977; Banz, 1981; Lakonishok e Shapiro, 1986; Fama e French, 1992) conduziu trabalhos que buscam explicar os diferentes fatores de risco além do fator beta $^{1}$ que podem determinar o retorno de um ativo. Dentre eles, destacase o modelo de três fatores de Fama e French que além do fator mercado, considera o tamanho da empresa (definido pelo valor de mercado do patrimônio líquido) e o índice book-to-market (relação entre o valor contábil e o valor de mercado do patrimônio líquido) como determinantes do retorno dos ativos.

\footnotetext{
${ }^{1}$ Relação entre a carteira de mercado, perfeitamente diversificada, e o ativo.

226 Revista Brasileira de Finanças (Online), Rio de Janeiro, Vol. 14, N.2, June 2016
} 
Estes trabalhos revelam a importância da volatilidade agregada para a teoria de carteiras e modelos de precificação de ativos. Porém, Campbell et al. (2001) indicam que esta volatilidade é apenas um dos componentes do retorno de uma ação individual e sugerem que choques em níveis setoriais (indústrias) e específicos das firmas (idiossincráticos) também são fatores indispensáveis para a mensuração do retorno de ativos.

Por meio do uso da metodologia proposta por Campbell et al. (2001), o presente trabalho deriva os componentes da volatilidade de uma ação (mercado, indústria e firma) para o mercado acionário brasileiro no período de 1996 a 2010 e verifica através de testes estatísticos (raiz unitária, quebra estrutural e tendência) se há presença de tendência estocástica ou determinística. Para o período amostral considerado neste estudo, foi observado que apenas o componente idiossincrático apresentou tendência significativa e de queda. Sugerem-se, também, algumas possibilidades para prováveis determinantes do comportamento apresentado pelas medidas de volatilidade. No entanto, uma investigação mais profunda sobre este tema será deixada para pesquisas futuras.

Desta forma, este trabalho complementa outros estudos brasileiros, na medida em que utiliza uma metodologia comumente empregada em pesquisas internacionais, mas pouco estudada no contexto brasileiro para analisar o comportamento dos componentes da volatilidade, principalmente do componente idiossincrático que, como apontado por Angelidis (2010), afeta decisões relativas à gestão de carteiras. ${ }^{2}$ Por exemplo, Campbell et al. (2001) mostram que, antes de 1985, 20 ações eram necessárias para reduzir o desvio padrão em excesso para $10 \%$ enquanto que em 1990 foi necessária uma carteira com 50 ações para atingir este nível de risco. Kearney e Poti (2008) chegaram a uma conclusão semelhante, relatando que 166 ações europeias foram necessárias para reduzir o risco idiossincrático em 2003, em comparação com 35 ações em 1974. Xu (2003) examina os benefícios da diversificação na China e argumenta, que recentemente, mais ações são necessárias para atingir um dado nível de risco.

Além desta introdução que contextualiza a pesquisa, define seus objetivos e discorre sobre sua relevância, o artigo é estruturado da seguinte forma: a seção 2 revisa a literatura relacionada ao tema,

\footnotetext{
${ }^{2}$ Se tudo o mais permanecer constante, um aumento no risco idiossincrático diminui a correlação entre o retorno das ações. 
enquanto a terceira seção detalha todos os passos, incluindo a escolha da amostra, a estimação das medidas de volatilidade e correlação média e os procedimentos metodológicos. A quarta seção apresenta os principais resultados encontrados. Por fim, a quinta seção traz as principais conclusões do estudo.

\section{Referencial Teórico}

A volatilidade idiossincrática está associada ao risco idiossincrático que é específico a um determinado ativo. Uma forma de precificá-la é pela parcela da variabilidade total do rendimento atrelada a fatores peculiares do ativo. Estudos têm mostrado (Falkenstein, 1996; Campbell et al., 2001; Xu e Malkiel, 2003) que nem sempre os investidores são capazes de diversificar o risco completamente, sendo o risco idiossincrático um importante fator para este tipo de investidor.

Falkenstein (1996) propõe que investidores possuem vantagem comparativa em comprar certos ativos o que faz com que diferentes tipos de investidores tenham carteiras enviesadas. Campbell et al. (2001) salientam que muitos investidores possuem grande quantidade de ações e falham em não diversificar da maneira correta ou têm suas participações restritas por políticas corporativas de remuneração. Além disso, fundos de investimento ou grandes instituições financeiras podem comprar elevada quantidade de ações de uma mesma empresa e influenciar seus preços, bem como a conduta de seus gestores. Este comportamento por parte do mercado é conhecido como institutional ownership que tem sido analisada (Campbell et al., 2001; Xu e Malkiel, 2003; Dennis e Strickland, 2004; Brandt et al., 2010) como um dos possíveis determinantes do comportamento da volatilidade idiossincrática.

Evidências foram encontradas de que a volatilidade idiossincrática aumentou ao longo do tempo, tanto em termos absolutos quanto em relação à variância do mercado e da indústria. Este efeito tem sido documentado nos mercados de ações dos EUA (Campbell et al., 2001; Xu e Malkiel, 2003; Boyer, Mitton e Vorkink, 2010; Brandt et al., 2010) e de países desenvolvidos e emergentes (Morck, Yu e Yeung, 2000; Li et al., 2004; Kearney e Potì, 2008).

Os resultados encontrados por Campbell et al. (2001) para ações do mercado acionário dos EUA no período de 1962 a 1997 sugerem que, apesar da volatilidade do mercado não apresentar nenhuma tendência visível, a volatilidade idiossincrática aumentou perceptivelmente. Como 
consequência do aumento da volatilidade idiossincrática em detrimento da volatilidade de mercado estável, a correlação média entre as ações diminuiu, assim como o poder do modelo de mercado. Além disso, Campbell et al. (2001) mostraram que as três medidas de volatilidade (mercado, indústria e firma) cresceram em momentos de recessão e ajudam a prever o crescimento do PIB.

Em busca de examinar as conclusões de Campbell et al. (2001) e até mesmo confrontá-las, pesquisas (Xu e Malkiel, 2003; Kearney e Potì, 2008; Sousa e Serra, 2008; Angelidis, 2010; Brandt et al., 2010; Bakaert et al., 2012) que utilizam a mesma metodologia ou que propõem novas abordagens para as medidas de volatilidade desagregada surgiram como consequência deste trabalho precursor.

Xu e Malkiel (2003) estudaram o comportamento da volatilidade idiossincrática para o período posterior à segunda Guerra Mundial no mercado acionário dos EUA. Utilizando dados mensais do Center for Reseach in Security Prices (CRSP) e uma abordagem diferente, onde a volatilidade idiossincrática foi construída diretamente pelos resíduos do modelo de três fatores de Fama e French (1993), eles encontraram que a volatilidade individual das ações aumentou ao longo do período analisado, confirmando as descobertas de Campbell et al. (2001). Segundo Xu e Malkiel (2003) esta tendência não é apenas atribuída à crescente importância da National Association of Securities Dealers Automated Quotations (NASDAQ), mas também ao montante de ações individuais que são detidas por uma mesma instituição financeira e aos objetivos das empresas em busca de maiores crescimentos.

Kearney e Potì (2008) examinaram a dinâmica do risco idiossincrático, risco de mercado e correlação dos retornos em 12 mercados de ações da zona do euro para o período de 1974 a 2004 utilizando-se do procedimento de Campbell et al. (2001) para decompor os componentes da volatilidade de uma ação, cuja construção foi feita com base em retornos semanais de cada ação para mensurar a volatilidade agregada mensal de cada componente. Eles encontraram uma tendência de alta na volatilidade idiossincrática e no risco de mercado enquanto que a correlação média das ações se manteve estável. Sousa e Serra (2008), utilizando-se também do método de Campbell et al. (2001) e de dados diários e semanais, documentaram os padrões da volatilidade mensal do mercado como um todo e específica da firma no mercado de ações português ao longo do período 1991 - 2005 e testaram explicações para o comportamento da volatilidade idiossincrática. Ao contrário de estudos 
anteriores, eles não encontram nenhuma evidência de aumento estatisticamente significante na volatilidade idiossincrática. Pelo contrário, a razão do risco específico em relação ao risco total caiu ligeiramente, apesar do componente idiossincrático ser dominante ao longo do período analisado. Mostraram que este resultado deriva da listagem de grandes empresas privatizadas que apresentam um baixo risco específico, pois a ponderação das firmas pequenas faz com que a tendência se torne estatisticamente insignificante.

Angelidus (2010) estudou as propriedades e implicações para a administração de carteiras de ativos da volatilidade idiossincrática de 24 países emergentes, incluindo o Brasil, durante o período de dezembro de 1994 até maio de 2007. O risco idiossincrático mensal foi construído com base nos resíduos de regressões feitas dos retornos diários de cada ação em função do retorno diário do mercado, cujos dados foram coletados da base de dados Datastream. Como resultado, eles reportam evidências contra a visão de que o aumento do risco idiossincrático é um fenômeno global. Em seus resultados, eles mostram que o risco específico do ativo não é significantemente maior do que foi no começo da década de 90 e que provavelmente há períodos de alta volatilidade seguidos por períodos de baixa volatilidade. Utilizando o modelo de mudança de regime de Hamilton (1989) eles mostram que durante o período de 1997 a 2000, a volatilidade idiossincrática muda para o regime de alta variância na maioria dos mercados emergentes, enquanto que para os anos após 2000, esses períodos de alto risco não foram observados na maioria dos mercados, o que evidencia que o aumento do risco idiossincrático se deve a períodos particulares da amostra e que tal tendência de aumento foi revertida em anos recentes.

Brandt et al. (2010), utilizando-se do mesmo procedimento de Campbell et al. (2001), analisaram se o comportamento da volatilidade idiossincrática nos EUA foi dado especificamente por variações nos retornos de ações de alto ou baixo preço e também se pode ser considerado um fenômeno episódico. Para tanto, os autores utilizaram dados que envolvem dois tipos de negociações: qualquer valor ou quantidade (1950 - 2007) e baixo valor (1983 - 2000), consideradas como proxy para investidores de varejo. A tendência de alta na volatilidade idiossincrática encontrada por Campbell et al. (2001) no período 1962 a 1997 alterou-se em 2003 com a volatilidade idiossincrática voltando aos níveis anteriores a 1990. A análise diferenciada pela característica da negociação indica que o fenômeno de alta se manifestou mais fortemente entre ações de baixo preço que é 230 Revista Brasileira de Finanças (Online), Rio de Janeiro, Vol. 14, N.2, June $2016 @()$ 
evidente apenas se essas ações são em sua maioria negociadas por investidores individuais (retail investors) e não por instituições conforme suspeitavam Xu e Malkiel (2003).

Bekaert et al. (2012) examinaram a volatilidade idiossincrática agregada em 23 países desenvolvidos durante os períodos de 1964-2008 e de 1980-2008 para o mercado americano e para os demais países considerados, respectivamente. Eles construíram o risco idiossincrático por meio da decomposição de Campbell et al. (2001) e pelos resíduos do modelo de três fatores de Fama e French (1996). Como resultado, eles não encontraram evidências de uma tendência de alta. Ao contrário, a volatilidade idiossincrática é bem descrita por um processo autoregressivo estacionário que ocasionalmente muda para um regime de alta variância de curta duração. Desta forma, seus resultados são consistentes com os de Brandt et al. (2010), os quais argumentam que o aumento da volatilidade na década de 90 foi temporária. Finalmente, Bekaert et al. (2012) documentam um novo fato empírico: a volatilidade idiossincrática está altamente correlacionada entre os países, e essas correlações tem aumentado no decorrer do tempo.

Como dito anteriormente, são poucas as pesquisas que investigam o risco idiossincrático no mercado acionário brasileiro. Galdi e Securato (2007) estudaram a questão se o risco idiossincrático ajuda a explicar o retorno de uma carteira diversificada de ativos no mercado acionário brasileiro. Esse artigo utilizou as quinze principais ações do Índice BOVESPA. Os dados foram coletados diariamente (dias úteis) e abrangem o período de 1999 a 2006. Para estimar o risco específico da carteira, Galdi e Securato (2007) isolaram o componente idiossincrático da variância dos retornos da carteira através da remoção da variância associada ao risco sistêmico. Galdi e Securato (2007) não encontraram evidências de que o risco idiossincrático contribua para a explicação do retorno de uma carteira.

Ricca (2010) estudou a relação entre volatilidade idiossincrática, assimetria idiossincrática e retorno da ação no Brasil no período de 1998 a 2009. Ambos os indicadores de risco idiossincrático foram construídos com base nos resíduos de regressão, aplicando o Modelo de Três Fatores de Fama e French para as sessenta e nove ações mais líquidas negociadas na Bolsa de Valores - BM \& FBOVESPA. Enquanto a volatilidade idiossincrática baseou-se na raiz quadrada da média dos resíduos ao quadrado, a assimetria idiossincrática foi construída como a soma dos resíduos elevada à terceira potência, dividida pela volatilidade 
idiossincrática elevada à terceira potência. $\mathrm{O}$ autor concluiu que a volatilidade idiossincrática foi maior para as carteiras com maior assimetria idiossincrática. Além disso, a carteira com a maior volatilidade idiossincrática e assimetria idiossincrática também exibiu retorno maior do que aquela com volatilidade e assimetria mais baixa.

Mendonça (2011) verificou a relação entre o risco idiossincrático e o retorno das ações no mercado brasileiro com uma amostra de 58 ações para o período de julho de 2005 a dezembro de 2010. Sua amostra, utilizando-se de dados diários, inclui todas as ações negociadas neste período, seguindo o critério adotado por Fu (2009), que exige que cada ação seja negociada por um mínimo de 15 dias em cada mês do período amostral. Por uma questão de conveniência, a pesquisa considerou apenas as ações presentes em todos os meses do período amostral. Para tanto, o autor calcula a volatilidade idiossincrática mensal de cada ativo através de dois métodos: a partir dos resíduos de regressões baseadas no modelo de três fatores de Fama e French (1992) e através do modelo EGARCH, o qual fornece a volatilidade condicional. As duas medidas de volatilidade idiossincrática foram adicionadas a modelos de regressões cross-section, juntamente com outras variáveis explicativas (beta, valor de mercado, índice book-to-market, efeito momentum e liquidez). Os resultados mostram que a volatilidade idiossincrática apresenta influência positiva e significante sobre o retorno e que o modelo de explicação mais apropriado é o que inclui todas as variáveis citadas utilizando a volatilidade idiossincrática estimada através dos resíduos do modelo de três fatores de Fama e French (1992).

Não obstante, tais estudos brasileiros não analisam a tendência dos componentes da volatilidade ao longo do tempo.

\section{Dados E Metodologia}

\subsection{Dados Utilizados}

A abordagem utilizada neste estudo obtém três componentes de volatilidade (mercado, indústria, firma) conforme proposto por Campbell et al. (2001). Não há restrição sobre o tipo de empresa listada, mas apenas liquidez. Desta forma, todas as ações negociadas na BM\&FBOVESPA em cada ano são candidatas a compor a amostra do presente estudo. Não necessariamente, a mesma quantidade de ações em um determinado ano permanecerá para os outros anos, pois a metodologia obtém medidas de 
volatilidade ponderadas que somadas representam a volatilidade do retorno de uma ação.

O critério adotado na escolha das ações por ano é a análise do índice de liquidez em bolsa, em termos anuais ${ }^{3}$. O critério de liquidez foi adotado para minimizar os problemas de retornos espúrios causados pela falta de preços de fechamento, tal como adotado também por Ricca (2010), já que o mercado acionário brasileiro é menor, mais recente e menos consolidado do que os mercados europeus e dos EUA. Abertura ou fechamento de capital, falências e falta de liquidez são as causas de tais dados faltantes. Cabe ressaltar que o critério adotado está sujeito a diversas críticas, principalmente pela possibilidade de ocorrer viés de seleção ou de sobrevivência. O elevado número de dados faltantes, no entanto, forçou tal escolha. Tanto este índice quanto os preços de fechamentos utilizados para mensurar as volatilidades e os valores de mercado usados como pesos são obtidos no sistema Economatica ${ }^{\circledR}$. A escolha das ações se faz por ano e por setor sendo que para este, adotouse a divisão setorial proposta pelo sistema Economatica®. As ações que estão entre os $20 \%$ maiores valores para o índice de liquidez em bolsa em cada setor e por ano, são as ações selecionadas para a composição da amostra. Além disso, ações com o valor do índice de liquidez superior a 0,5 serão inseridas mesmo que não estejam no filtro anterior em função da possibilidade de possuírem alta liquidez, mas pertencerem a um determinado setor com poucas ações. Os filtros sugeridos geraram uma amostra final variando de um mínimo de 98 ações em 1996 a um máximo de 139 ações em 2007.

Todos os retornos foram calculados de forma contínua, isto é, usouse o logaritmo natural da razão entre os fechamentos (ajustados aos proventos) em $t$ e $t$ - 1 , onde $t$ pode ser de qualquer periodicidade (diário, semanal, mensal ou anual).

\subsection{Decomposição da Volatilidade}

Os setores (indústrias) estudados são os disponibilizados pelo banco de dados do sistema Economatica ${ }^{\circledR}$. As indústrias são denotadas por um

\footnotetext{
${ }^{3}$ líquidez em bolsa $=100 * p / P * \operatorname{sqrt}(n / N * v / V)$, onde: $p$ é o número de dias em que houve pelo menos um negócio com a ação dentro do período escolhido; $P$ é o número total de dias do período escolhido; $n$ é o número de negócios com a ação dentro do período escolhido; $N$ é o numero de negócios com todas as ações dentro do período escolhido; $v$ é o volume em dinheiro com a ação dentro do período escolhido; $V$ é o volume em dinheiro com todas as ações dentro do período escolhido. 
subscrito $i$ e as firmas individuais são indexadas por $j$. $\mathrm{O}$ excesso de retorno da firma $j$ que pertence à indústria $i$ no período $t$ é denotado por $R_{j i t}$. Este excesso de retorno, como todos os outros, é mensurado como um excesso de retorno sobre a taxa overnight apurada no Sistema Especial de Liquidação e de Custódia (Selic) que também foi extraída do sistema Economatica ${ }^{\circledR}$. $W_{j i t}$ é o peso da empresa $j$ na indústria $i$ no período $t$. Tal metodologia é válida para algum arbitrário regime de ponderação. Para o peso da empresa $i$ no período $t$ usamos seu valor de mercado do período $t-1$, e assim, consideramos tais pesos como constantes no período $t$. O excesso de retorno da indústria $i$ em $t$ é dado por $R_{i t}=\sum_{j \epsilon \mathrm{i}} W_{j i t} R_{j i t}$. O peso da indústria $i$ no mercado total é denotado por $W_{i t}$, e o excesso de retorno do mercado é $R_{m t}=\sum_{\mathrm{i}} W_{i t} R_{i t}$.

A decomposição proposta por Campbell et al. (2001) pode ser definida como uma modificação do modelo CAPM onde o intercepto é definido igual a zero nas seguintes equações:

$$
R_{i t}=\beta_{i m} R_{m t}+\tilde{\epsilon}_{i t}
$$

para o retorno da indústria. Para o retorno das firmas, temos a equação (2),

$$
R_{j i t}=\beta_{j i} R_{i t}+\tilde{\eta}_{j i t}=\beta_{j i} \beta_{i m} R_{m t}+\beta_{j i} \tilde{\epsilon}_{i t}+\tilde{\eta}_{j i t}
$$

Na equação (1), $\beta_{i m}$ é o beta da indústria $i$ em relação ao retorno de mercado e $\tilde{\epsilon}_{i t}$ é o resíduo específico da indústria. Similarmente, na equação (2), $\beta_{j i}$ é o beta da firma $j$ na indústria $i$ com relação ao retorno da sua indústria e $\tilde{\eta}_{j i t}$ é o resíduo específico da firma. Por construção, $\tilde{\eta}_{j i t}$ é ortogonal aos componentes $R_{m t}$ e $\tilde{\epsilon}_{i t}$. Em outras palavras, o beta da firma $j$ com relação ao mercado, $\beta_{j m}$, satisfaz $\beta_{j m}=\beta_{j i} \beta_{i m}$. A soma ponderada dos diferentes betas é igual à unidade:

$$
\sum_{i} w_{i t} \beta_{i m}=1, \quad \sum_{j \epsilon i} w_{j i t} \beta_{j i}=1 .
$$

A decomposição (1) e (2) garante que os diferentes componentes do retorno de uma firma são ortogonais entre si. Por isso, viabiliza uma 
simples decomposição de variância em que todos os termos de covariância sejam iguais a zero:

$\operatorname{Var}\left(R_{i t}\right)=\beta_{i m}^{2} \operatorname{Var}\left(R_{m t}\right)+\operatorname{Var}\left(\tilde{\epsilon}_{i t}\right)$,

$\operatorname{Var}\left(R_{j i t}\right)=\beta_{j m}^{2} \operatorname{Var}\left(R_{m t}\right)+\beta_{j i}^{2} \operatorname{Var}\left(\tilde{\epsilon}_{i t}\right)+\operatorname{Var}\left(\tilde{\eta}_{j i t}\right)$.

Uma dificuldade originada é a necessidade de conhecer os betas específicos de cada firma que são difíceis de estimar e podem ser instáveis ao longo do tempo. Assim, Campbell et al. (2001) propuseram um modelo simplificado que não requer a estimação de betas. Tal abordagem permite uma decomposição de variância similar às equações (4) e (5).

Não obstante, considere a seguinte decomposição simplificada do retorno da indústria que elimina a presença de qualquer beta na criação da volatilidade desagregada:

$$
R_{i t}=R_{m t}+\epsilon_{i t}
$$

onde $\epsilon_{i t}$ é definido como a diferença entre o retorno da indústria, $R_{i t}$, e o retorno do mercado, $R_{m t}$. Campbell, Lo e MacKinlay (1997) referem a tal equação como um modelo de retorno de mercado ajustado ${ }^{4}$ em contraste com o modelo de retorno de mercado do Capital Asset Pricing Model (CAPM). Comparando as equações (1) e (6), temos que:

$\epsilon_{i t}=\tilde{\epsilon}_{i t}+\left(\beta_{i m}-1\right) R_{m t}$

Por conseguinte, os resíduos das equações (1) e (6) serão iguais apenas se $\beta_{i m}=1$ ou $R_{m t}=0$ e $\operatorname{COV}\left(R_{m t}, \epsilon_{i t}\right)$ não pode ser desconsiderada em função da não ortogonalidade entre estes dois componentes. Computar a variância do retorno da indústria produz:

$$
\begin{aligned}
\operatorname{VAR}\left(R_{i t}\right) & =\operatorname{VAR}\left(R_{m t}\right)+\operatorname{VAR}\left(\epsilon_{i t}\right)+2 \operatorname{COV}\left(R_{m t}, \epsilon_{i t}\right), \\
& =\operatorname{VAR}\left(R_{m t}\right)+\operatorname{VAR}\left(\epsilon_{i t}\right)+2\left(\beta_{i m}-1\right) \operatorname{VAR}\left(R_{m t}\right) .
\end{aligned}
$$

\footnotetext{
${ }^{4}$ Pode ser visto como um modelo de mercado restrito que força a constante igual a zero e $\beta_{i}$ igual a 1. Derivado do seguinte modelo de mercado: $R_{i t}=\alpha_{i}+\beta_{i} R_{m t}+\epsilon_{i t}$, onde $\mathrm{E}\left[\epsilon_{i t}\right]=0$ e $\operatorname{VAR}\left[\epsilon_{i t}\right]=\sigma_{\epsilon i}^{2}$.
}

@. () Revista Brasileira de Finanças (Online), Rio de Janeiro, Vol. 14, N. 2, June 2016 
O que Campbell et al. (2001) encontraram como solução é que embora o retorno individual contenha termos de covariância, a média ponderada da variância entre indústrias é livre de covariâncias individuais:

$$
\begin{aligned}
\sum_{i} w_{i t} \operatorname{VAR}\left(R_{i t}\right) & =\operatorname{VAR}\left(R_{m t}\right)+\sum_{i} w_{i t} \operatorname{VAR}\left(\epsilon_{i t}\right), \\
& =\sigma_{m t}^{2}+\sigma_{\epsilon t}^{2},
\end{aligned}
$$

onde $\sigma_{m t}^{2} \equiv \operatorname{Var}\left(R_{m t}\right)$ e $\sigma_{\epsilon t}^{2} \equiv \sum_{i} w_{i t} \operatorname{Var}\left(\epsilon_{i t}\right)$. Os termos envolvem betas agregados, pois a partir da equação (3) $\sum_{i} w_{i t} \beta_{i m}=1$. Portanto, podemos utilizar o resíduo, $\epsilon_{i t}$, na equação (6) para construir uma medida de volatilidade média da indústria que não requer nenhuma estimação de betas. A média ponderada $\sum_{i} w_{i t} V A R\left(R_{i t}\right)$ pode ser interpretada como a volatilidade esperada para uma indústria aleatória sendo que a probabilidade de se escolher a indústria $i$ é igual ao seu peso, $W_{i t}$.

O mesmo procedimento é adotado para o retorno das firmas individuais. Observe a seguinte equação:

$R_{j i t}=R_{i t}+\eta_{j i t}$,

que define $\eta_{j i t}$ como:

$\eta_{j i t}=\tilde{\eta}_{j i t}+\left(\beta_{j i}-1\right) R_{i t}$

Logo, a variância do retorno da firma será

$\operatorname{VAR}\left(R_{j i t}\right)=\operatorname{VAR}\left(R_{i t}\right)+\operatorname{VAR}\left(\eta_{j i t}\right)+2 \operatorname{COV}\left(R_{i t}, \eta_{j i t}\right)$,

$\operatorname{VAR}\left(R_{j i t}\right)=\operatorname{VAR}\left(R_{i t}\right)+\operatorname{VAR}\left(\eta_{j i t}\right)+2\left(\beta_{j i}-1\right) \operatorname{VAR}\left(R_{i t}\right)$.

A média ponderada da variância da firma na indústria $i$ é, portanto:

$\sum_{j \in i} w_{j i t} \operatorname{VAR}\left(R_{j i t}\right)=\operatorname{VAR}\left(R_{i t}\right)+\sigma_{\eta i t}^{2}$,

onde $\sigma_{\eta i t}^{2} \equiv \sum_{j \in i} W_{j i t} \operatorname{VAR}\left(\eta_{j i t}\right)$ é a volatilidade média da firma $j$ na indústria $i$. Tomando a média ponderada entre indústrias e usando a 
equação (10), produz-se novamente uma decomposição de variância livre de betas:

$\sum_{i} w_{i t} \sum_{j \in i} W_{j i t} \operatorname{VAR}\left(R_{j i t}\right)=$

$$
\begin{aligned}
& \sum_{i} W_{i t} \operatorname{VAR}\left(R_{i t}\right)+\sum_{i} W_{i t} \sum_{j \epsilon i} W_{j i t} \operatorname{VAR}\left(\eta_{j i t}\right), \\
= & \operatorname{VAR}\left(R_{m t}\right)+\sum_{i} W_{i t} \operatorname{VAR}\left(\epsilon_{i t}\right)+\sum_{i} W_{i t} \sigma_{\eta i t}^{2}, \\
= & \sigma_{m t}^{2}+\sigma_{\epsilon t}^{2}+\sigma_{\eta t}^{2},
\end{aligned}
$$

onde $\sigma_{\eta t}^{2} \equiv \sum_{i} W_{i t} \sigma_{\eta i t}^{2}=\sum_{i} W_{i t} \sum_{j \epsilon i} W_{j i t} V A R\left(\eta_{j i t}\right)$ é a média ponderada da volatilidade em nível de firma entre todas as firmas.

Assim, é possível construir as medidas de volatilidade desagregadas: volatilidade do mercado, volatilidade da indústria e volatilidade da firma. Para tanto, usou-se fechamentos semanais $(s)$ das ações selecionadas para mensurar a volatilidade esperada mensal para cada componente de volatilidade. A menos que seja referido, a partir de agora $t$ e $s$ representam periodicidade mensal e semanal, respectivamente.

A volatilidade amostral do retorno de mercado no mês $t, M K T_{t}$, é computada como:

$M K T_{t}=\hat{\sigma}_{m t}^{2}=\sum_{s \in t}\left(R_{m s}-\mu_{m s}\right)^{2}$,

onde $\mu_{m s}$ é definido como a média do retorno de mercado, $R_{m s}$, ao longo do mês $t$. Para fechamentos semanais temos que $R_{m s}=\sum_{\mathrm{i}} W_{i s} R_{i s}$. Os pesos são baseados no valor de mercado de cada firma que em $t$ será o valor de mercado em $t$ - 1 . Consideramos os pesos constantes dentro do período $t$. Ou seja, o valor de mercado mensal em $t$-l, não sofrerá alterações no decorrer das semanas em $t$.

Para a volatilidade na indústria $i$, somam-se os quadrados dos resíduos específicos da equação (6) dentro do período $t$,

$\hat{\sigma}_{\epsilon i t}^{2}=\sum_{s \in t} \epsilon_{i s}^{2}$

Para que as covariâncias entre as indústrias se cancelem é preciso fazer a média ponderada. Isso produz a seguinte medida de volatilidade média para a indústria, 


$$
I N D_{t}=\sum_{i} W_{i t} \hat{\sigma}_{e i t}^{2} .
$$

Estimar a volatilidade específica da firma (idiossincrática) é feita de uma maneira similar. Primeiro somam-se os quadrados dos erros específicos da equação (11) para cada firma no período amostral:

$\hat{\sigma}_{\eta j i t}^{2}=\sum_{s \in t} \eta_{j i s}^{2}$

depois, faz-se a média ponderada da volatilidade específica da firma dentro de uma indústria:

$\hat{\sigma}_{\eta i t}^{2}=\sum_{j \in i} W_{j i t} \hat{\sigma}_{\eta j i t}^{2}$.

Por último, a média ponderada das indústrias para obter uma medida de volatilidade média das firmas:

FIRM $_{t}=\sum_{i} W_{i t} \hat{\sigma}_{\eta i t}^{2}$

\subsection{Correlação Média}

O desempenho da volatilidade idiossincrática pode afetar o comportamento da correlação média tanto para cima, em caso de queda da volatilidade idiossincrática, como para baixo, caso contrário. Por sua vez, a correlação média é uma proxy para movimentos em conjunto dos retornos das ações que segundo Li et al. (2004) pode ser um indicativo de mercado ineficiente, tais como bolhas ou herd behavior.

Nessa linha de raciocínio, Morck, Yu e Yeung (2000) encontraram que preços de ações em economias com maior PIB per capita se movem de uma maneira não sincronizada. Em contraste, os preços das ações tendem a se mover junto tanto para cima quanto baixo em economias com menor PIB per capita. Analogamente, a razão entre a variação idiossincrática e a variação total dos retornos de ações individuais foi maior em economias de maior renda em meados de 1990 e segundo os autores tal característica está associada com o forte direito de propriedade destes mercados. Por outro lado, a maior sincronia no movimento dos preços das ações em economias pobres é consequência da maior participação do componente sistemático na variação total dos retornos. 
Para a mensuração da correlação média entre as ações, usamos um estimador não condicional desta medida. Para fins de comparação, foi obtida a correlação média ponderada pelo valor de mercado de cada ação e um estimador igualmente ponderado. $\mathrm{O}$ principal fator que tem levado pesquisadores (Merton, 1980; Campbell et al.,2001; Kearney e Potì, 2008; Pollet e Wilson, 2010) a utilizarem este estimador é a sua praticidade.

Para tanto, considere a equação (22), que proporciona a correlação entre cada par de ações $a$ e $b$ no mês $t$ :

$\hat{\rho}_{a b, t}=\frac{\sum_{s=1}^{s}\left(R_{a, s}-\bar{R}_{a, t}\right)\left(R_{b, s}-\bar{R}_{b, t}\right)}{\sqrt{\sum_{s=1}^{s}\left(R_{a, s}-\bar{R}_{a, t}\right)^{2} \sum_{s=1}^{s}\left(R_{b, s}-\bar{R}_{b, t}\right)^{2}}}$,

onde $R_{a, s}$ é o retorno da ação $a$ na semana $s ; R_{b, s}$ é o retorno da ação $b$ na semana $s$ e $\bar{R}_{a, t}$ e $\bar{R}_{b, t}$ representam o retorno médio das ações $a$ e $b$ no mês $t$.

Obtidas as correlações entre cada par de ações $a$ e $b$ através da equação (22), a correlação média entre as $n$ ações é originada computando-se a média ponderada das correlações, como segue:

$\operatorname{CORR}_{t}=\sum_{a \neq b}^{n} \sum_{b=1}^{n} w_{a t} w_{b t} \hat{\rho}_{a b, t}$

Para o caso de ponderação diferenciada, $w_{a t}$ e $w_{b t}$ são os valores de mercado das ações $a$ e $b$ no período $t$ dividido pela soma dos valores de mercado das $n$ ações observadas no mês $t$. Já para o índice igualmente ponderado assume-se que $w_{a t}=w_{b t}=1 / n$. Denotamos $\operatorname{CORRVM}_{t}$ a medida de correlação média ponderada pelo valor de mercado e $C O R R I P_{t}$ a correlação média igualmente ponderada.

\subsection{Testes de raiz unitária na ausência de quebras estruturais}

Uma abordagem frequentemente usada para avaliar a presença de raiz unitária em séries temporais é o teste de Dickey-Fuller aumentado (Dickey e Fuller 1981). Por meio dele é possível verificar se uma série $\left\{y_{t}\right\}$ apresenta raiz unitária assumindo um processo autoregressivo $\operatorname{AR}(p)$ com termos de diferenças defasadas de $y_{t}$ para controlar a 
autocorrealação dos erros. Dickey e Fuller (1981) consideram três diferentes especificações para a regressão-teste:

$\Delta y_{t}=\gamma y_{t-1}+\sum_{i=2}^{p} \beta_{i} \Delta y_{t-i+1}+\varepsilon_{t}$

$\Delta y_{t}=a_{0}+\gamma y_{t-1}+\sum_{i=2}^{p} \beta_{i} \Delta y_{t-i+1}+\varepsilon_{t}$

$\Delta y_{t}=a_{0}+a_{2} t+\gamma y_{t-1}+\sum_{i=2}^{p} \beta_{i} \Delta y_{t-i+1}+\varepsilon_{t}$.

O parâmetro de interesse $(\gamma)$ é estimado por mínimos quadrados ordinários (MQO). Comparando a estatística $t$ de $\gamma\left(t_{\gamma}\right)$ com o valor critico apropriado do teste, testamos a hipótese nula $(\gamma=0)$ contra a alternativa $(\gamma<0)$. Se $\gamma=0,\left\{y_{t}\right\}$ contém uma raiz unitária. Maiores detalhes sobre este teste podem ser encontrados no trabalho de Dickey e Fuller (1981).

Alternativamente, Phillips-Perron (1988) propõem um método não paramétrico para controle de correlações seriais de ordem maior nos erros. Enquanto o teste ADF adiciona termos de diferenças defasados para contornar estes casos, o teste PP efetua uma correção nãoparamétrica da estatística $t$ do coeficiente $\gamma\left(t_{\gamma}\right)$ das equações de ADF, de forma a se ajustar à correlação serial dos erros $\varepsilon_{t}$.

A regressão-teste de PP é

$\Delta y_{t}=B^{\prime} D_{t}+\gamma y_{t-1}+\varepsilon_{t}$,

onde $\varepsilon_{t}$ não possui raíz unitária e pode apresentar heterocedasticidade e $D_{t}$ é um vetor de termos determinísticos (intercepto ou intercepto e tendência determinística) como aqueles incluídos no teste ADF. O teste PP acomoda qualquer ordem de correlação serial e heterocedasticidade nos erros $\varepsilon_{t}$ ao modificar $t_{\gamma}$ da seguinte forma:

$Z_{t}=\left(\frac{\widehat{\sigma}^{2}}{\widehat{\lambda}^{2}}\right)^{1 / 2} \cdot t_{\gamma=0}-\frac{1}{2}\left(\frac{\widehat{\lambda}^{2}-\widehat{\sigma}^{2}}{\widehat{\lambda}^{2}}\right) \cdot\left(\frac{T \cdot S E(\widehat{\gamma})}{\widehat{\sigma}^{2}}\right)$.

$S E(\hat{\gamma})$ é o erro padrao de $\hat{\gamma}$ e os termos $\hat{\sigma}^{2}$ e $\hat{\lambda}^{2}$ são estimativas consistentes dos parâmetros de variância, onde 240 Revista Brasileira de Finanças (Online), Rio de Janeiro, Vol. 14, N.2, June 2016 
$\sigma^{2}=\lim _{T \rightarrow \infty} T^{-1} \sum_{t=1}^{T} E\left[\varepsilon_{t}^{2}\right]$ e $\lambda^{2}=\lim _{T \rightarrow \infty} \sum_{t=1}^{T} E\left[T^{-1} S_{T}^{2}\right]$, tal que $S_{T}=\sum_{t=1}^{T} \varepsilon_{t}$. Desta forma, $\hat{\sigma}^{2}$ e $\hat{\lambda}^{2}$ são estimados pelo método de Newey-West $(1987)^{5}$. Assim, o teste PP apresenta vantagens sobre o teste $\mathrm{ADF}$, pois é robusto à presença de heterocedasticidade nos erros $\varepsilon_{t}$ e não exige a especificação da ordem do processo autoregressivo. Sob a hipótese nula de que $\gamma=0$, a estatística $Z_{t}$ tem a mesma distribuição assintótica da estatística $t_{\gamma}$ do teste ADF.

Contudo, surgiram críticas às abordagens dos testes ADF e PP, principalmente no que tange à perca de poder quando há uma raiz próxima da região de não-estacionariedade. Uma maneira para lidar com este problema é o uso do teste de estacionaridade de KPSS, proposto por Kwiatowski, Phillips, Schmidt e Shin (1992).

Basicamente, a diferença entre o teste KPSS e os testes ADF e PP é que esses dois últimos consideram na hipótese nula que a série seja integrada de ordem 1 (I(1)) enquanto o teste KPSS assume na hipótese nula que a série é integrada de ordem $0(I(0))$, ou seja, a série é estacionária em nível, sendo desnecessário tomar as primeiras diferenças. Em linhas gerais, o teste KPSS tem como base o modelo abaixo:

$y_{t}=\underline{B}^{\prime} D_{t}+\mu_{t}+\varepsilon_{t}$

$\mu_{t}=\mu_{t-1}+e_{t}$

onde $e_{t}$ é um processo estacionário com média zero e variância constante $\sigma_{e}^{2}, D_{t}$ contém termos determinísticos (intercepto ou intercepto e tendência determinística) e $\varepsilon_{t}$ é $I(0)$ e pode apresentar heterocedasticidade. A hipótese nula de que $y_{t}$ é $I(0)$ é formulada como $H_{0}: \sigma_{e}^{2}=0$, o que implica que $\mu_{t}$ é uma constante. A estatística do teste KPSS é o multiplicador de Lagrange ou a estatística "score" para testar $\sigma_{e}^{2}=0$ contra a hipótese alternativa de que $\sigma_{e}^{2}>0$, e é dada por:

KPSSt $=\left(T^{-2} \sum_{t=1}^{T} \hat{S}_{t}^{2}\right) / \hat{\lambda}^{2}$,

\footnotetext{
${ }^{5}$ Newey e West (1987) propuseram um estimador para a matriz de variância-covariância dos resíduos consistente na presença de heteroscedasticidade e/ou autocorrelacação serial de forma não conhecida. Tal método é utilizado para impedir que os erros padrões dos parâmetros estimados sejam enviesados.
} 
onde $\hat{S}_{t}=\sum_{j=1}^{t} \hat{\varepsilon}_{j}, \quad \hat{\varepsilon}_{t}$ é o resíduo da regressão de $y_{t}$ em função de $D_{t}$, e $\hat{\lambda}^{2}$ é uma estimativa consistente de um dos parâmetros da variância de longo prazo de $\varepsilon_{t}$, como definido anteriormente, ou seja, $\hat{\lambda}^{2}$ pode ser um estimador de Newey e West (1987).

\subsection{Testes de raiz unitária na presença de quebra estrutural}

Aplicar testes de raiz unitária que permitem a presença de quebra estrutural em séries temporais é uma alternativa que deve ser considerada. Segundo Glynn, Perera e Verma (2007), testes robustos à presença de quebra estrutural impedem que o resultado seja enviesado na direção de não rejeição da hipótese nula. Deste modo, aplicamos o teste de Lee e Strazicich (2003), cuja vantagem sobre os demais testes é que ele permite incluir duas quebras, tanto sob a hipótese nula quanto sob a alternativa e considera quebras tanto no nível quanto na tendência determinística da série. Lumsdaine e Papell (1997) argumentam que aplicar um teste que permite apenas uma quebra quando na verdade há mais de uma, implica em perda do poder do teste, e Nunes, Newbold e Kuan (1997) e Lee e Strazicich (2001) evidenciam que assumir nenhuma quebra sob a hipótese nula em testes de quebras endógenas faz com que a estatística do teste divirja, levando a rejeições significantes da hipótese nula de raíz unitária quando na verdade os dados contêm raiz unitária com quebras.

A estatística do teste de raiz unitária de Lee e Strazicich (2003) pode ser estimada por regressão como segue:

$$
\Delta y_{t}=\delta^{\prime} \Delta Z_{t}+\phi \tilde{S}_{t-1}+u_{t}
$$

onde $Z_{t}$ é um vetor de variáveis exógenas; $\tilde{S}_{t}=y_{t}-\tilde{\psi}_{x}-Z_{t} \tilde{\delta}$, para $t=$ $2, \ldots, \mathrm{T} ; \tilde{\delta}$ são os coeficientes da regressão de $\Delta y_{t}$ sobre $\Delta Z_{t} ; \tilde{\psi}_{x}$ é dado por $y_{1}-Z_{1} \tilde{\delta}$; e $y_{1}$ e $Z_{1}$ denotam as primeiras observações de $y_{t}$ e $Z_{t}$, respectivamente. Duas quebras estruturais podem ser consideradas como segue: um modelo com duas quebras no nível da série, descrito como $Z_{t}=\left[1, t, D_{1 t}, D_{2 t}\right]^{\prime}$, onde $D_{j t}=1$ para $t \geq T_{B_{j}}+1, j=1,2$, e 0 caso contrário. $T_{B_{j}}$ denota o período quando a quebra ocorre; e b) um modelo com duas quebras no nível e na tendência determinística, descrito como $Z_{t}=\left[1, t, D_{1 t}, D_{2 t}, D T_{1 t}, D T_{2 t}\right]^{\prime}$, onde $D T_{j t}=t-T_{B_{j}}$ para $t \geq T_{B_{j}}+1, j$ $=1,2$, e 0 caso contrário. 
Finalmente a hipótese nula é descrita por $\phi=0$. No caso de erros autocorrelacionados, termos de diferenças defasados de $\Delta \tilde{S}_{t-1}, j=1, \ldots, k$, podem ser incluídos na equação (31) como no teste DF.

Por fim, o procedimento de Lee e Strazicich (2003) considera qualquer ponto da série como um potencial ponto de quebra estrutural $\left(T_{B_{j}}\right)$ e estima uma regressão para cada possível ponto de quebra sequencialmente. Entre todos os possíveis pontos de quebra $\left(T_{B_{j}}\right)$, o procedimento seleciona aquele que minimiza a estatística do teste para testar $\phi=0$. Como é típico de testes de quebras endógenas, um recorte é definido de tal modo que os pontos finais da amostra não sejam incluídos no teste, isto é, a região de recorte é definida como $[r \mathrm{~T},(1-r) \mathrm{T}]$ para algum $r \in(0,1)$ e $\mathrm{T}$ é o tamanho amostral. Lee e Strazicich (2003) sugere um $r$ de 0.1 para eliminar os pontos finais.

\subsection{Testes de Quebra Estrutural}

Em busca de não incorrer em respostas errôneas para os testes de raiz unitária aplicados nas séries estudadas, foi realizado o teste de quebra estrutural proposto por Bai e Perron $(1998,2003)$ que considera a possibilidade de quebras múltiplas ocorrendo em datas desconhecidas em modelos de regressão linear estimados por MQO. Além disso, a possibilidade de identificar quando a quebra ocorreu através destes procedimentos, fornece subsídios para analisar se a mudança de comportamento de uma variável está associada à política de governo, crise econômica ou outros fatores.

Segundo Bai e Perron $(1998,2003)$ a maior parte dos testes econométricos relacionados à quebra estrutural são projetados para o caso de apenas uma única quebra exógena e que, desta forma, testes que busquem determinar endogenamente mudanças múltiplas precisam ser considerados. Para tanto, os autores propuseram um modelo de quebra estrutural parcial onde nem todos os parâmetros não estão sujeitos a mudanças, permite formas gerais de correlação serial e heteroscedasticidade nos erros, variáveis dependentes defasadas, regressores de tendência, assim como diferentes distribuições para os erros e regressores em todos os segmentos.

Resumidamente, o procedimento parte da seguinte regressão com $m$ quebras ( $m+1$ regimes): 
$y_{t}=x_{t}^{\prime} \beta+z_{t}^{\prime} \delta_{j}+\varepsilon_{t}, t=T_{j-1}+1, \ldots, T_{j}, j=1, \ldots, m+1$,

onde $T_{0}=0$ e $T_{m+1}=T$. $y_{t}$ é a variável dependente observada, $x_{t}(p \times 1) \mathrm{e}$ $z_{t}$ (qx1) são vetores de variáveis de controle e $\beta$ e $\delta_{j}(j=1, \ldots, m+1)$ são os correspondentes vetores de coeficientes; $\varepsilon_{t}$ é o termo de erro. Assume-se que os índices $\left(T_{1}, \ldots, T_{m}\right)$, ou pontos de quebra, são desconhecidos. O objetivo é estimar os coeficientes desconhecidos da regressão juntamente com os pontos de quebra. Note que este é um modelo de quebra estrutural parcial no sentido de que $\beta$ não está sujeito às mudanças de regime, e por isso é estimado usando toda a amostra. Se $p$ $=0$, obtemos um modelo de quebra estrutural puro, onde todos os coeficientes estão sujeitos às mudanças de regime. O método de MQO é aplicado em cada uma das $m$ partições $\left(T_{1}, \ldots, T_{m}\right)$ de forma a minimizar a soma dos quadrados dos resíduos:

$\sum_{i=1}^{m+1} \sum_{t=T_{i-1}+1}^{T_{i}}\left[y_{t}-x_{t}^{\prime} \beta-z_{t}^{\prime} \delta_{i}\right]^{2}$.

Denote $\hat{\beta}\left(T_{j}\right)$ e $\hat{\delta}\left(T_{j}\right)$ como as estimativas resultantes de cada partição $m\left(T_{1}, \ldots, T_{m}\right)$. Substituindo essas estimativas na função objetivo e denotando a soma dos quadrados dos resíduos resultante como $S_{T}\left(T_{1}, \ldots, T_{m}\right)$, os pontos de quebra estrutural estimados $\left(\widehat{T}_{1}, \ldots, \widehat{T}_{m}\right)$ são tais que

$\left(\widehat{T}_{1}, \ldots, \widehat{T}_{m}\right)=\operatorname{argmin}_{T_{1, \ldots,}, T_{m}} S_{T}\left(T_{1}, \ldots, T_{m}\right)$,

onde a minimização é tomada sobre todas as partições $\left(T_{1}, \ldots, T_{m}\right)$ de forma que $\left(T_{i}, \ldots, T_{i-1}\right) \geq q$. Assim, os estimadores dos pontos de quebra são minimizadores globais da função objetivo. As propriedades estatísticas dos estimadores resultantes e o conjunto de hipóteses podem ser conferidos em Bai e Perron (1998).

Bai e Perron (2003) apresentam um algoritmo baseado no princípio da programação dinâmica que permite a computação das estimativas dos pontos de quebra como minimizadores globais da soma dos quadrados dos resíduos. Resumidamente, os passos sugeridos por Bai e Perron (2003) para obter o número de quebras são: primeiro, utilizar o teste $U d \max$ e verificar se pelo menos uma quebra está presente; a partir disso, o número de quebras pode ser decidido baseado na análise do teste 
$\operatorname{SupF}(l+1 / l)$ como forma de verificar se há alguma quebra adicional na série. Udmax testa a não existência de quebras contra um número desconhecido de quebras dado um limite superior M. Já o teste $\operatorname{SupF}(l+$ $1 / l$ ) é aplicado de forma seqüencial por aumentar $l$ até que o teste falhe em rejeitar a hipótese nula de não existir quebra adicional. $\mathrm{O}$ teste analisa a soma dos quadrados dos resíduos obtida com $l$ quebras e a soma dos quadrados dos resíduos que é obtida com $l+1$ quebras. A hipótese nula é rejeitada se o valor mínimo da soma dos quadrados dos resíduos (sobre todos os segmentos onde uma quebra adicional está incluída) é suficientemente menor que a soma dos quadrados dos resíduos do modelo com $l$ quebras. Assim, a data de quebra selecionada é associada com esse mínimo total.

\subsection{Testes de tendência linear}

Uma abordagem padrão para testar a significância da tendência determinística de uma série temporal tem sido a de assumir um modelo linear simples, da forma:

$y_{t}=\beta_{1}+\beta_{2} t+u_{t}, \quad t=1,2,3, \ldots, T$,

onde $y_{t}$ é a variável dependente e $u_{t}$ é o erro estocástico do modelo de tendência. $\mathrm{O}$ parâmetro $\beta_{2}$ mede a mudança média de $y_{t}$ por período de tempo. Uma vez que todas as séries estudadas são bastante persistentes, testes padrões não são válidos. Desta forma, realizamos os seguintes testes unicaudais:

$H_{0}: \beta_{2} \geq 0 \quad H_{1}: \beta_{2}<0$ ou $H_{0}: \beta_{2} \leq 0 \quad H_{1}: \beta_{2}>0$,

utilizando a estatística $t-P S_{T}$ proposta por Vogelsang (1998), que é robusta para qualquer forma de correlação serial em $u_{t}$. $O$ teste de tendência usado oferece várias vantagens sobre os testes convencionais. Em primeiro lugar, o teste é robusto para a possibilidade de uma raiz unitária no termo do erro, ou seja, é assintoticamente válido se os erros são estacionários ou se possuem raiz unitária. Vogelsang (1998) mostrou que em amostras finitas o teste tem o tamanho ótimo próximo do nível nominal em amostras tão pequenas quanto 100 observações. Em segundo lugar, o teste não requer uma estimativa de $\sigma^{2}$, e assim, a escolha do 
truncamento da defasagem do erro pode ser totalmente evitada (Fomby e Vogelsang, 2002).

A estatística $t-P S_{T}$ é baseada na seguinte regressão que é obtida computando as somas parciais dos dados originais $y_{t}$.

$z_{t}=\beta_{1} t+\beta_{2}\left[\frac{1}{2}\left(t^{2}+t\right)\right]+S_{t}$

onde $z_{t}=\sum_{j=1}^{t} y_{j}$ e $S_{t}=\sum_{j=1}^{t} u_{j} . z_{t}$ e $S_{t}$ são as somas parciais de $y_{t}$ e $u_{t}$ e os regressores são obtidos pelas fórmulas $t=\sum_{j=1}^{t} 1 \mathrm{e} \frac{1}{2}\left(t^{2}+t\right)=$ $\sum_{j=1}^{t} j$. Suponha que a regressão (37) é estimada por MQO. Seja $X_{z}$ a matriz $(T \times 2)$ dos regressores de (37) e $t_{z}$ a estatística- $t$ padrão de MQO para testar $\beta_{2}=0$. Ou seja,

$t_{z}=\tilde{\beta}_{2} /\left[s_{z}^{2}\left(X_{z}^{\prime} X_{z}\right)^{-1}\right]^{1 / 2}$,

onde $\tilde{\beta}_{2}$ denota o estimador MQO de $\beta_{2}$ da equação (37), $s_{z}^{2}=$ $(T-2)^{-1} \sum_{t=1}^{T} \tilde{S}_{t}^{2}$ é a variância amostral dos resíduos de MQO.

A estatística $t-P S_{T}$ proposta por Vogelsang (1998) é definida por $T^{-1 / 2}$ vezes a expressão (38):

$t-P S_{T}=T^{-1 / 2} t_{z} \exp \left(-b J_{T}\right)$,

onde $b$ é uma constante e $J_{T}=\left(R S S_{y}-R S S_{J}\right) / R S S_{J}$. $R S S_{y}$ é a soma dos quadrados dos resíduos de MQO da regressão (37) e $R S S_{J}$ é a soma dos quadrados dos resíduos de MQO da regressão:

$y_{t}=\beta_{1}+\beta_{2} t+\sum_{i=2}^{9} \beta_{i+1} t^{i}+u_{t}$

Note que T vezes $J_{T}$ corresponde à estatística padrão de Wald para $\operatorname{testar} \beta_{3}=\beta_{4}=\cdots=\beta_{10}=0$ na regressão (40).

Vogelsang (1998) recomendou que a ordem do polinômio da equação (40) seja igual a 9 , pois o poder do teste $t-P S_{T}$ é uma função crescente da ordem do polinômio, mas o aumento do poder é desprezível para ordens polinomiais maiores que 9 . 
Quando os erros têm uma raiz unitária, $\exp \left(-b J_{T}\right)$ tem uma distribuição assintótica bem definida, porém quando os erros são estacionários, $\exp \left(-b J_{T}\right) \rightarrow 1$, já que $J_{T} \rightarrow 0$. Assim, quando os erros são estacionários, $t-P S_{T}$ e $T^{-1 / 2} t_{z}$ possuem as mesmas distribuições assintóticas porque $\exp \left(-b J_{T}\right) \rightarrow 1$. Mas, quando os erros têm uma raiz unitária, $t-P S_{T}$ e $T^{-1 / 2} t_{z}$ possuem distribuições assintóticas diferentes. Mais importante, note que para $b>0, \exp \left(-b J_{T}\right)$ assume valores pequenos porque $J_{T}$ assume grandes valores positivos. Portanto, $b$ pode ser escolhido de forma a diminuir a distribuição assintótica de $t-P S_{T}$ quando os erros têm uma raiz unitária sem afetar a distribuição assintótica de $t-P S_{T}$ quando os erros são estacionários.

Não é possível escolher $b$ de modo que a distribuição de $t-P S_{T}$ seja a mesma se os erros são estacionários ou se têm uma raiz unitária. Mas, para um dado nível de significância, $b$ pode ser escolhido de forma que os valores críticos são os mesmos, seja para erros estacionários ou para erros com raiz unitária. Vogelsang (1998) derivou a distribuição assintótica de $t-P S_{T}$ e calculou os valores críticos assintóticos e os valores correspondentes de $b$ utilizando métodos de simulação de Monte Carlo. Para pontos percentuais 1\%, 5\% e 10\%, os valores críticos assintóticos e os $b$ 's (em parênteses) são 2.647 (1.501), 1.720 (0.716) e 1.331 (0.494). Esses valores críticos são apropriados para a hipótese unicaudal que estamos considerando.

\section{Resultados}

A partir da amostra selecionada foi possível mensurar as três séries temporais que representam a volatilidade de mercado, indústria e firma no período de janeiro de 1996 a dezembro de 2010. Cada série é caracterizada como uma representatividade de quanto o componente, em média, é responsável pela volatilidade total de uma ação qualquer no mês observado. Além disso, obteve-se a correlação média conforme elucidado na subseção 3.3 da metodologia. 
Tabela 1

Estatísticas Descritivas

\begin{tabular}{llllll}
\hline & $M K T$ & $I N D$ & FIRM & CORRVM & CORRIP \\
\hline Média & 0,07 & 0,06 & 0,07 & 0,13 & 0,15 \\
Mediana & 0,03 & 0,04 & 0,04 & 0,13 & 0,13 \\
Desvio padrão & 0,12 & 0,05 & 0,10 & 0,08 & 0,12 \\
Curtose & 28,74 & 9,68 & 16,86 & $-0,61$ & 1,28 \\
Assimetria & 4,80 & 2,72 & 3,75 & 0,30 & 0,58 \\
Mínimo & 0,00 & 0,01 & 0,01 & $-0,01$ & $-0,23$ \\
Máximo & 0,98 & 0,33 & 0,71 & 0,34 & 0,52 \\
N & 180 & 180 & 180 & 180 & 180 \\
\hline
\end{tabular}

Fonte: os autores.

A tabela 1 mostra as estatísticas descritivas das séries propostas e a tabela 2 apresenta a composição da amostra por setor e por ano. Pode-se observar que os setores com maior representatividade em termos de quantidade de ações são Energia Elétrica, Finanças e Seguros, Alimentos e Bebidas, Outros, Siderurgia e Metalurgia e Telecomunicações.

As figuras 1 a 4 foram elaboradoras em busca de produzir uma impressão mais rápida do fenômeno em estudo, permitindo dessa forma que se tenha uma visão global da variação dos dados. Assim, as figuras 1 a 3 apresentam os resultados dos três componentes da variância estimados mensalmente usando dados semanais: volatilidade do mercado $\left(M K T_{t}\right)$, volatilidade da indústria $\left(I N D_{t}\right)$ e volatilidade da firma $\left(F I R M_{t}\right)$. Todas as três séries foram anualizadas (multiplicadas por 12). 
Tabela 2

Quantidade de ações selecionadas por ano e por setor

\begin{tabular}{|c|c|c|c|c|c|c|c|c|c|c|c|c|c|c|c|}
\hline SETORES & ఫ্ঠু & $\overrightarrow{8}$ & $\begin{array}{l}\vec{D} \\
\end{array}$ & $\overline{0}$ & 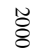 & $\stackrel{\tilde{o}}{\circ}$ & 芯 & 芯 & 芳 & 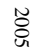 & 垎 & 论 & $\underset{\infty}{\tilde{O}}$ & 若 & $\stackrel{n}{\circ}$ \\
\hline AGRO E PESCA & 1 & 1 & 1 & 1 & 1 & 1 & 1 & 1 & 1 & 1 & 1 & 1 & 1 & 1 & 1 \\
\hline ALIMENTOS E BEBIDAS & 9 & 14 & 15 & 16 & 18 & 15 & 15 & 15 & 16 & 16 & 18 & 22 & 20 & 19 & 6 \\
\hline COMERCIO & 4 & 4 & 3 & 4 & 3 & 3 & 3 & 3 & 3 & 5 & 6 & 5 & 6 & 6 & 6 \\
\hline CONSTRUÇÃO & 2 & 2 & 2 & 2 & 3 & 3 & 3 & 3 & 4 & 3 & 3 & 6 & 6 & 6 & 7 \\
\hline ELETROELETRÔNICOS & 4 & 4 & 4 & 4 & 4 & 4 & 3 & 3 & 2 & 2 & 2 & 3 & 2 & 2 & 2 \\
\hline ENERGIA ELÉTRICA & 7 & 8 & 11 & 13 & 14 & 14 & 14 & 14 & 15 & 14 & 14 & 15 & 14 & 13 & 14 \\
\hline FINANÇAS E SEGUROS & 9 & 10 & 10 & 9 & 10 & 9 & 9 & 9 & 9 & 8 & 8 & 12 & 11 & 12 & 10 \\
\hline MÁQUINAS INDUST. & 2 & 2 & 2 & 2 & 2 & 2 & 2 & 2 & 2 & 2 & 2 & 2 & 2 & 2 & 2 \\
\hline MINERAÇÃO & 2 & 2 & 2 & 2 & 2 & 2 & 2 & 3 & 3 & 3 & 2 & 2 & 3 & 3 & 3 \\
\hline MINERAIS NÃO MET. & 1 & 1 & 1 & 1 & 2 & 2 & 2 & 1 & 1 & 1 & 1 & 1 & 1 & 1 & 1 \\
\hline OUTROS & 13 & 13 & 14 & 15 & 17 & 14 & 14 & 14 & 15 & 15 & 17 & 21 & 20 & 20 & 15 \\
\hline PAPEL E CELULOSE & 4 & 4 & 4 & 4 & 3 & 3 & 3 & 3 & 4 & 3 & 3 & 3 & 3 & 2 & 2 \\
\hline PETROLEO E GAS & 2 & 2 & 2 & 2 & 2 & 3 & 3 & 2 & 2 & 3 & 2 & 2 & 2 & 3 & 3 \\
\hline QUIMICA & 8 & 8 & 8 & 8 & 8 & 8 & 7 & 7 & 7 & 6 & 6 & 6 & 6 & 4 & 5 \\
\hline SOFTWARE E DADOS & - & - & - & - & - & - & - & - & - & - & - & - & - & - & - \\
\hline $\begin{array}{l}\text { SIDERURGIA E } \\
\text { METALURGIA }\end{array}$ & 11 & 11 & 10 & 11 & 11 & 11 & 11 & 10 & 10 & 10 & 10 & 10 & 9 & 8 & 8 \\
\hline TELECOMUNICAÇÕES & 4 & 6 & 13 & 13 & 19 & 15 & 14 & 14 & 13 & 11 & 9 & 7 & 7 & 6 & 4 \\
\hline TEXTIL & 8 & 8 & 8 & 9 & 8 & 8 & 9 & 7 & 8 & 9 & 8 & 9 & 9 & 9 & 9 \\
\hline TRANS. E SERV. & 1 & 1 & 1 & 1 & 1 & 1 & 1 & 2 & 2 & 4 & 6 & 5 & 5 & 5 & 5 \\
\hline VEICULOS E PEÇAS & 6 & 6 & 6 & 6 & 6 & 6 & 6 & 6 & 6 & 5 & 5 & 7 & 5 & 5 & 5 \\
\hline
\end{tabular}

Fonte: os autores.

A análise da figura 1 demonstra que $M K T_{t}$ foi maior em períodos de crises, tanto internacionais (Asia em 1997, Rússia 1998, 11 de setembro e do "Subprime" em 2008) quanto nacionais (cambial de 1999 e eleições 2002), o que condiz com a hipótese de que a volatilidade dos retornos dos ativos é maior em momentos de crises.

Os $10 \%$ maiores valores observados para $M K T_{t}$ estão entre o intervalo 0.14 e 0.98 . Neste, tal medida apresentou em média um desvio padrão anualizado de $57 \%$ e dentre as 18 observações, 15 referem-se a 
períodos de oscilações ocasionadas por fatores macroeconômicos tanto internacionais quanto nacionais. As crises da Ásia (1997), Rússia (1998), 11 de setembro e "Subprime" (2008) são os momentos de maior presença neste intervalo para $M K T_{t}$. A característica apresentada por $M K T_{t}$ também foi observada nos estudos de Campbell et al. (2001), Kearney e Potì (2008), Sousa e Serra (2008) e Brandt et al. (2010).

\section{Figura 1}

Volatilidade do mercado $\left(\mathrm{MKT}_{\mathrm{t}}\right)$

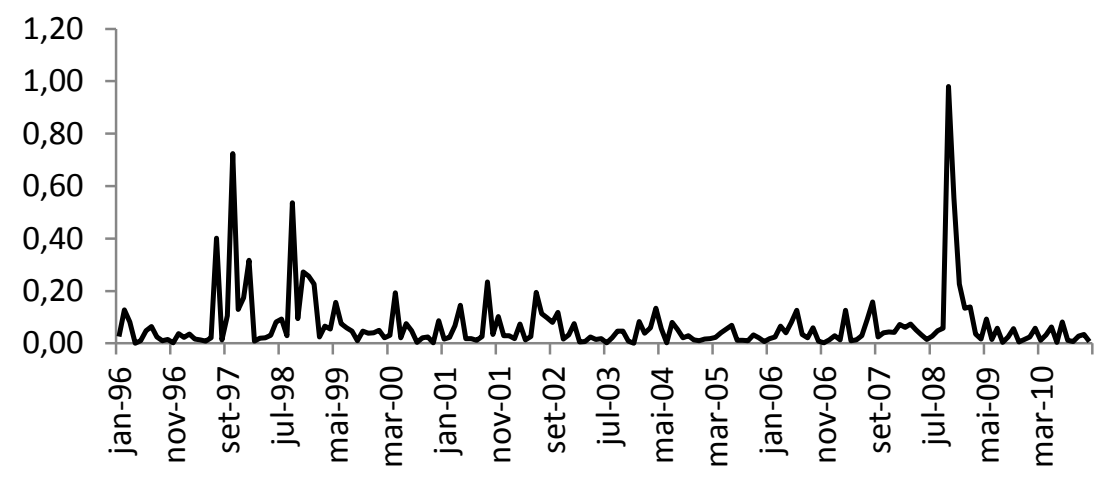

Nota: Variância anualizada dentro de cada mês dos retornos semanais, obtida através da equação (16) para o período de janeiro de 1996 a dezembro de 2010.

\section{Figura 2}

Volatilidade da Indústria $\left(I N D_{t}\right)$

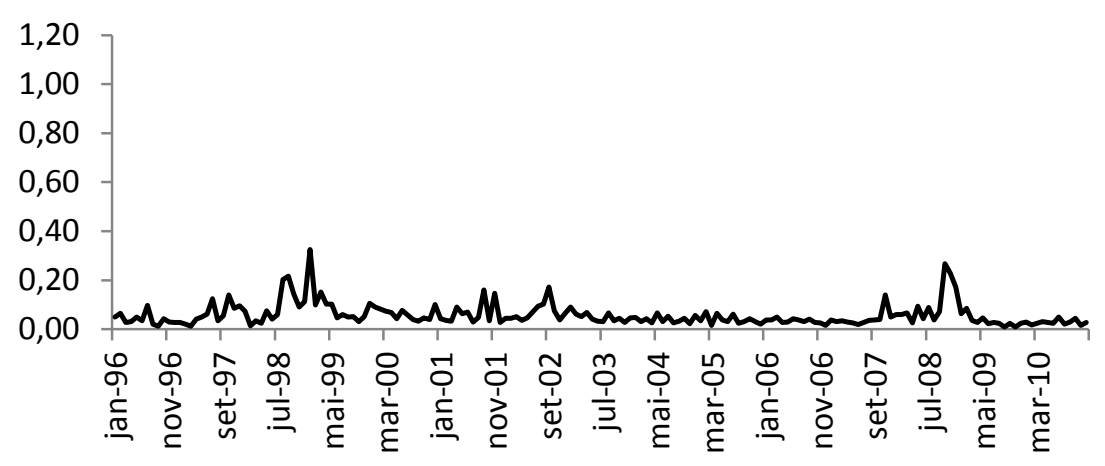

Nota: Variância anualizada dentro de cada mês dos retornos semanais das indústrias relativo ao retorno de mercado, calculada usando a equações (17) e (18), para o período de janeiro de 1996 a dezembro de 2010 . 
Na figura 2 observa-se o comportamento da volatilidade da indústria (setores). Comparada com a volatilidade do mercado a volatilidade da indústria é menor em média. $\mathrm{O}$ valor máximo de $M K T_{t}$ para todo o período amostral ocorreu em outubro de 2008 (0.98, que implica em um desvio padrão anualizado de $99 \%$ representando o grande impacto da crise do "Subprime" sobre a volatilidade dos preços das ações) enquanto que para $I N D_{t}$ foi em janeiro de 1999 (0.32, desvio padrão anualizado de $57 \%$ como consequência da alteração no câmbio para flutuante).

Classificar $\boldsymbol{I N} \boldsymbol{D}_{\boldsymbol{t}}$ em relação aos $10 \%$ maiores valores, assim como $\boldsymbol{M K T _ { t }}$, permitiu observar que nove destes valores são comuns entre os dois intervalos sendo que todos eles se referem a momentos de grande incerteza gerados por fatores internacionais ou nacionais. Desta forma,

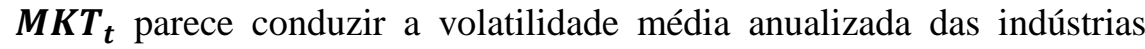
(setores). IN $\boldsymbol{D}_{\boldsymbol{t}}$ apresentou neste intervalo um valor médio de 0.17 que implica em um desvio padrão médio anualizado de $40 \%$.

\section{Figura 3}

Volatilidade da Firma $\left(F I R M_{t}\right)$

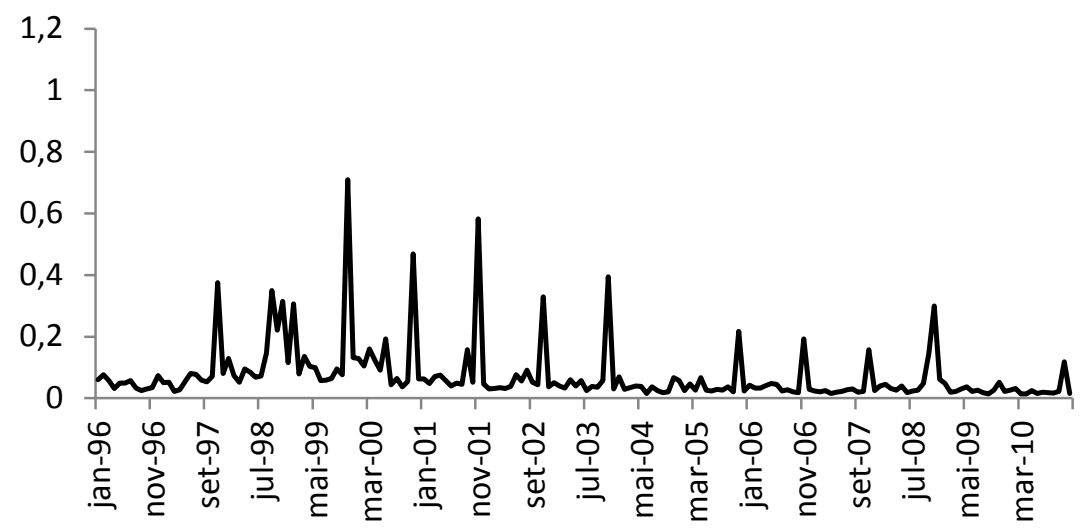

Nota: Variância anualizada dos retornos semanais das firmas relativo à indústria de cada firma, calculada usando a equações (19) - (21), para o período de janeiro de 1996 a dezembro de 2010.

A figura 3 mostra o comportamento da volatilidade das firmas que representa a participação média do componente idiossincrático na volatilidade total de uma ação qualquer ao longo dos meses. A primeira impressão que temos ao observar a figura 3 é que $F I R M_{t}$ apresenta 
sazonalidade. Assim, aplicamos um ajustamento sazonal ${ }^{6}$ nesta medida de volatilidade com o objetivo de retirar movimentos cíclicos que se repetem frequentemente através do procedimento Census X12 ${ }^{7}$. Foi possível verificar que $F I R M_{t}$ realmente apresenta sazonalidade ao nível de significância de $1 \%$. Em busca de um melhor ajuste para os modelos e testes propostos, utilizamos, para $F I R M_{t}$, a série resultante do procedimento Census X12 que é livre da presença de sazonalidade.

Em função da dificuldade de se observar a presença de tendência em qualquer uma das medidas de volatilidade na inspeção das figuras 1,2 e 3, obteve-se uma média móvel de ordem 12 sobre as séries originais que possibilitou melhor visualização do comportamento dos componentes ao longo do período estudado. Assim, como pode ser visto na figura 4, há indícios de uma provável tendência de queda em FIRM . Uma característica interessante é que em primeiro momento parece que entre janeiro de 1996 e dezembro de 1998 a volatilidade das firmas apresentou uma grande ascensão e posteriormente mostrou-se decrescente, indicando a presença de quebra estrutural nesta medida de volatilidade. O mercado acionário brasileiro mostrou-se diferente da maioria dos estudos realizados em outros países, onde a volatilidade das firmas teve tendência de crescimento.

\section{Figura 4}

Volatilidade anualizada MA (12)

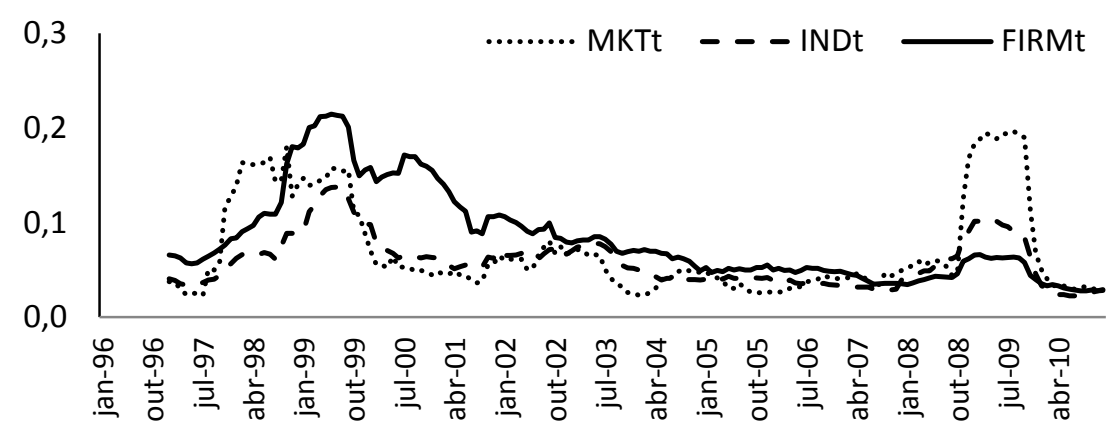

Nota: Média móvel mensal de ordem 12 para $\boldsymbol{M K T}_{\boldsymbol{t}}, \boldsymbol{I N \boldsymbol { D } _ { \boldsymbol { t } }}$ e $\boldsymbol{F I R \boldsymbol { M } _ { \boldsymbol { t } }}$.

\footnotetext{
${ }^{6} \mathrm{O}$ teste também foi aplicado nas outras medidas de volatilidade e correlação, mas os resultados não indicaram a presença de sazonalidade.

${ }^{7}$ Mais detalhes sobre o procedimento podem ser encontrados no sítio do U.S. Census Bureau.

252 Revista Brasileira de Finanças (Online), Rio de Janeiro, Vol. 14, N.2, June 2016 
Outro fator aparente na figura 4 é que $F I R M_{t}$ tem se tornado a medida de volatilidade com menor peso sobre a volatilidade de uma ação qualquer nos últimos anos. Além disso, nos últimos meses as três medidas de volatilidade apresentaram comportamento semelhante no que tange às suas participações na volatilidade total de uma ação.

Uma importante questão é se a tendência inicialmente apresentada por FIRM $_{t}$ se trata de uma tendência estocástica ou determinística. A primeira impressão é de uma tendência estocástica devido à persistente flutuação na volatilidade mostrada nas figuras 1,2 e 3.

Tabela 3

Estrutura de Autocorrelação Serial

\begin{tabular}{|c|c|c|c|c|c|}
\hline$\rho$ & FIRM $_{t}$ & $I N D_{t}$ & $M K T_{t}$ & $\mathrm{CORRVM}_{t}$ & $\mathrm{CORRIP}_{t}$ \\
\hline 1 & 0.586 & 0.48 & 0.314 & 0.184 & 0.077 \\
\hline 2 & 0.144 & 0.204 & 0.087 & -0.036 & 0.031 \\
\hline 3 & 0.234 & 0.04 & 0.179 & 0.161 & 0.095 \\
\hline 4 & 0.222 & 0.099 & -0.13 & -0.006 & -0.007 \\
\hline 5 & -0.003 & 0.013 & -0.074 & 0.037 & 0.052 \\
\hline 6 & 0.079 & -0.118 & -0.001 & 0.118 & 0.028 \\
\hline 7 & -0.017 & -0.006 & -0.011 & -0.048 & -0.086 \\
\hline 8 & 0.053 & -0.001 & 0.065 & -0.059 & 0.081 \\
\hline 9 & 0.055 & -0.006 & -0.019 & 0.013 & 0.045 \\
\hline 10 & -0.077 & 0.063 & -0.038 & 0.011 & -0.021 \\
\hline 11 & 0.149 & 0.11 & 0.137 & 0.039 & 0.15 \\
\hline 12 & -0.037 & -0.001 & -0.065 & 0.01 & -0.032 \\
\hline
\end{tabular}

Fonte: os autores.

A tabela 3 mostra que existe autocorrelação serial em defasagens superiores para as medidas de volatilidade, levantando assim, a possibilidade de que elas contenham raiz unitária. Para tanto, testes foram realizados com o objetivo de verificar a estacionariedade ou não das séries. Como discutido anteriormente, deve-se tomar cuidado na realização de testes de raiz unitária em uma série temporal caso exista suspeita de mudanças estruturais (o caso de $F I R M_{t}$ ). Se a presença destas se confirma, as várias estatísticas dos testes $\mathrm{ADF}$ e PP são enviesadas em @) Revista Brasileira de Finanças (Online), Rio de Janeiro, Vol. 14, N. 2, June $2016 \quad 253$ 
direção a não rejeição de raiz unitária, mesmo sendo a série estacionaria dentro de cada um dos subperíodos. Um condicionante favorável à presença de quebras é que durante o período estudado (1996-2010) ocorreram mudanças estruturais econômicas que poderiam alterar o comportamento de longo prazo das séries.

\section{Tabela 4}

Resultados do teste de Bai e Perron $(1998,2003)^{8}$

\begin{tabular}{|c|c|c|c|c|c|c|c|}
\hline$y_{t}$ & Modelo especificado & $\mathrm{m}$ & Udmax & $\operatorname{SupF}(2 / 1)$ & $\operatorname{SupF}(3 / 2)$ & Data & IC $95 \%$ \\
\hline \multirow[t]{2}{*}{ FIRM } & $y_{t}=\delta_{0, j}+\delta_{1, j} t+\delta_{2, j} y_{t-1}+\varepsilon_{t}$ & 3 & $23.10^{* * * *}$ & $13.58^{* *}$ & 8.35 & $05 / 2000$ & $05 / 2000-11 / 2001$ \\
\hline & & & & & & $11 / 2007$ & $01 / 2007-03 / 2008$ \\
\hline
\end{tabular}

\begin{tabular}{|c|c|c|c|c|c|c|c|}
\hline & $y_{t}=\delta_{0, j}+\delta_{1, j} t+\delta_{2, j} y_{t-1}+\varepsilon_{t}$ & 3 & 11.36 & - & - & \multicolumn{2}{|c|}{ MKT } \\
\hline IND & $y_{t}=\delta_{0, j}+\delta_{1, j} t+\delta_{2, j} y_{t-1}+\delta_{3, j} y_{t-2}+\varepsilon_{t}$ & 3 & 9.99 & - & - & - & - \\
\hline CORRVM & $y_{t}=\delta_{0, j}+\delta_{1, j} t+\delta_{2, j} y_{t-1}+\varepsilon_{t}$ & 3 & 9.82 & - & - & - & - \\
\hline CORRIP & $y_{t}=\delta_{0, j}+\delta_{1, j} t+\delta_{2, j} y_{t-1}+\varepsilon_{t}$ & 3 & 7.43 & ـ & - & - & - \\
\hline
\end{tabular}

Nota: (***): $1 \%$ de significância; (**): $5 \%$ de significância; $(*) 10 \%$ de significância. Fonte: os autores.

A tabela 4 apresenta os resultados para os testes propostos por Bai e Perron $(1998,2003)$. Para todas as variáveis incluímos uma tendência determinística e a própria variável dependente defasada na matriz de regressores cujos parâmetros estão sujeitos às mudanças de regime para evitar possível autocorrelação nos resíduos. O número de termos defasados para cada variável foi determinado por regressões à parte de forma a se obter resíduos não autocorrelacionados. Analisando a Tabela 4 podemos ver que o teste $U d \max$ rejeita a hipótese nula de nenhuma quebra em favor da hipótese alternativa de um número qualquer de quebras ao nível de significância de $1 \%$ apenas para FIRM $_{t}$. Portanto, a única série com possível presença de quebra estrutural é $F I R M_{t}$. A partir disso, utiliza-se o teste $\operatorname{SupF}(l+1 / l)$ para inferir sobre a quantidade de quebras existentes. Por conseguinte, rejeitamos a hipótese nula de apenas uma quebra em favor da hipótese alternativa de duas quebras, $\operatorname{Sup} F(2 /$ 1). Outro resultado da abordagem de Bai e Perron $(1998,2003)$ é a data das quebras, que para $F_{I R M_{t}}$ a primeira quebra aconteceu em maio de

\footnotetext{
${ }^{8}$ Resultados obtidos utilizando código GAUSS disponível no site de Pierre Perron. 254 Revista Brasileira de Finanças (Online), Rio de Janeiro, Vol. 14, N.2, June 2016
} 
2000 com um intervalo de $95 \%$ de confiança entre maio de 2000 e novembro de 2001 e a segunda quebra aconteceu em novembro de 2007 com um intervalo de $95 \%$ de confiança entre janeiro de 2007 e março de 2008.

A figura 5 apresenta a série $F I R M_{t}$ dessazonalizada e é possível observar graficamente o ponto de quebra estimado pelos testes de Bai e Perron $(1998,2003)$. A primeira e a segunda quebra são indicadas pelas linhas sólidas e tracejadas, respectivamente. Podemos ver uma quebra de tendência a partir da data da primeira quebra (maio de 2000) e a segunda quebra que ocorreu em novembro de 2007 pode ter sido devida ao colapso da bolha imobiliária americana, com início em outubro de 2007. Podemos ver um pico na série de FIRMt próximo de novembro de 2008, causado provavelmente pela crise mundial do mercado de ações de outubro de 2008, o que poderia ter levado o teste a indicar uma quebra estrutural.

\section{Figura 5}

Linha de tendência com uma quebra estrutural

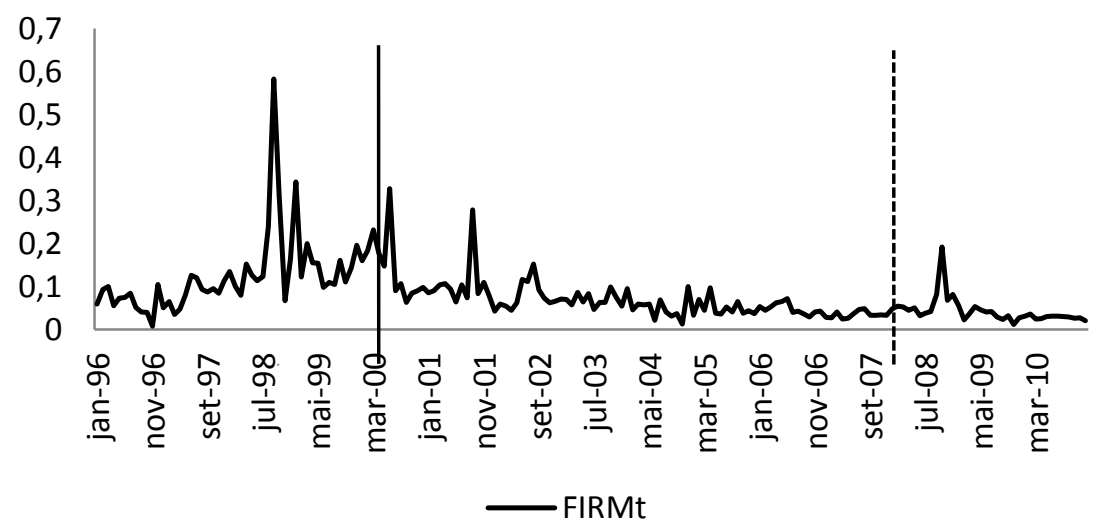

Dessa forma, o objetivo de utilizar o procedimento de Bai e Perron $(1998,2003)$ foi identificar de forma endógena a quantidade de quebras estruturais de cada uma das variáveis estudadas, pois o tipo de teste de raiz unitária a ser usado na presença de quebras estruturais varia em função da quantidade destas e da forma como são identificadas. Como o teste de Bai e Perron $(1998,2003)$ identificou duas quebras para $F I R M_{t}$, utilizamos o teste de raiz unitária proposto por Lee e Strazicich (2003), 
que permite a presença de duas quebras estruturais determinadas de forma endógena tanto sob a hipótese nula quanto sob a alternativa. Já para as outras séries $\left(I N D_{t}, M K T_{t}, C O R R V M_{t}, C O R R I P_{t}\right)$ usamos os testes tradicionais (ADF e PP).

\section{Tabela 6}

Teste de raiz unitária para a série com quebra estrutural

\begin{tabular}{llllll}
\hline \multicolumn{6}{l}{ Lee e Strazicich (2003) } \\
\hline Série & Constante & Tendência & $\mathrm{t}$ & $1^{\mathrm{a}}$ quebra & $2^{\mathrm{a}}$ quebra \\
\hline \multirow{2}{*}{ FIRM $_{t}$} & Sim & Não & $-7.508^{* * * *}$ & $08 / 1998$ & $01 / 1999$ \\
& $\operatorname{sim}$ & Sim & $-10.786^{* * * *}$ & $04 / 1998$ & $09 / 2000$ \\
\hline
\end{tabular}

Nota: (***): $1 \%$ de significância; (**): $5 \%$ de significância; $(*) 10 \%$ de significância. Os valores críticos do teste podem ser encontrados na Tabela 2 de Lee e Strazicich (2003). Os termos de diferenças defasadas incluídos na equação (31) para controlar possível correlação serial foram determinados pelo método de seleção "general para específico" seguindo Lee e Strazicich (2003).

A tabela 6 apresenta os resultados do teste Lee e Strazicich (2003) para $F_{I R M_{t}}$ e a tabela 7 para as séries sem quebras estruturais. Através do teste de Lee e Strazicich (2003) a hipótese nula de presença de raiz unitária em FIRM $_{t}$ é rejeitada ao nível de significância de $1 \%$. Desta forma, conclui-se que $F I R M_{t}$ é estacionária com a possível presença de duas quebras estruturais. Outro resultado interessante do teste de Lee e Strazicich (2003) é que a segunda quebra dada pelo modelo com quebra na tendência e na constante está próxima à de Bai e Perron (2003), que foi em maio de 2000 com intervalo de $95 \%$ de confiança entre maio e novembro de 2001 . 
Tabela 7

Teste de Raiz Unitária para as séries sem quebra estrutural

\begin{tabular}{|c|c|c|c|c|c|c|}
\hline \multicolumn{5}{|c|}{ Dickey-Fuller Aumentado (ADF) ${ }^{\mathrm{a}}$} & \multicolumn{2}{|c|}{ Phillips - Perron (PP) } \\
\hline Série & Constante & Tendência & Estatistica t & $\begin{array}{l}\text { Valor } \\
\text { Crítico 5\% }\end{array}$ & Estatistica $\mathrm{t}$ & $\begin{array}{l}\text { Valor } \\
\text { Crítico 5\% }\end{array}$ \\
\hline \multirow{2}{*}{$M K T_{t}$} & $\operatorname{sim}$ & não & -9.60 & -2.87 & -9.85 & -2.87 \\
\hline & $\operatorname{sim}$ & $\operatorname{sim}^{*}$ & -9.62 & -3.43 & -9.86 & -3.43 \\
\hline \multirow{2}{*}{$I N D_{t}$} & $\operatorname{sim}$ & não & -5.43 & -2.87 & -8.41 & -2.87 \\
\hline & $\operatorname{sim}$ & $\operatorname{sim}^{*}$ & -5.61 & -3.43 & -8.51 & -3.43 \\
\hline \multirow{2}{*}{$\operatorname{CORRVM}_{t}$} & $\operatorname{sim}$ & não & -10.95 & -2.87 & -11.02 & -2.87 \\
\hline & $\operatorname{sim}$ & $\operatorname{sim}$ & -11.26 & -3.43 & -11.22 & -3.43 \\
\hline \multirow{2}{*}{ CORRIP $_{t}$} & $\operatorname{sim}$ & não & -11.57 & -2.87 & -11.42 & -3.99 \\
\hline & $\operatorname{sim}$ & $\operatorname{sim}$ & -11.88 & -3.43 & -11.62 & -4.55 \\
\hline
\end{tabular}

Nota: Esta tabela apresenta testes de raiz unitária para as séries de volatilidade e correlação construídas com dados semanais. $M K T_{t}$ é a volatilidade de mercado obtida através da equação (16), $I N D_{t}$ é a volatilidade da indústria construída das equações (17) e (18), e $C O R R V M_{t}$ e $C O R R I P_{t}$ são as correlações médias construídas das equações (22) a (23). Todas as medidas são variâncias e correlações ponderadas. (*) não significante. $\left({ }^{a}\right)$ as defasagens utilizadas no teste ADF foram definidas pelo critério SIC.

Fonte: os autores.

A tabela 7 permite observar que as séries $I N D_{t}, M K T_{t}, C O R R V M_{t}, C O R R I P_{t}$ são estacionárias de acordo com os testes $\mathrm{ADF}$ e $\mathrm{PP}^{9}$, uma vez que a estatística $t$ destes testes permite rejeitar a hipótese nula de não estacionariedade ao nível de significância de 5\%. Dada a estacionariedade das séries abordadas, buscamos verificar a possibilidade de uma tendência determinística linear utilizando todas as variáveis em nível ao invés de em diferenças.

Estimamos os modelos de tendência (equação 35) para todo o período amostral $\left(1996\right.$ - 2010) para cada série e apenas em $F I R M_{t}$ dividimos a amostra em antes e após a quebra estrutural de maio de 2000 que foi encontrada através da abordagem de Bai e Perron (1998, 2003), cuja data de quebra se encontra próxima à da quebra de setembro de 2000 encontrada pelo teste de Lee e Strazicich (2003). Como podemos ver tanto na figura da volatilidade anualizada de FIRMt (figura 4) como na de sua série dessazonalizada (figura 5) que FIRMt apresenta uma tendência

\footnotetext{
${ }^{9}$ Utilizamos o teste KPSS como forma de verificar os resultados dos testes. As conclusões sobre estacionariedade são as mesmas obtidas pelos testes ADF e PP. Ao contrário destes, a hipótese nula do teste KPSS é que a série é estacionária.
} 
de queda após o ano de 2000. Examinando a tabela 8, observa-se que $M K T_{t}, I N D_{t}$ e $F I R M_{t}$ apresentaram uma tendência negativa ao longo do período estudado (1996-2010), dada pelos valores negativos de $\widetilde{\beta}_{2}$. No entanto, apenas para $F I R M_{t}$ a tendência foi significativa ao nível de $5 \%$ de significância. Veja que a estatística calculada de $t-P S_{T}(-1.7409)^{10}$ é menor que seu valor crítico (-1.720), como nosso teste é unicaudal à esquerda (36), rejeitamos a hipótese nula de uma tendência nula ou positiva e aceitamos a hipótese alternativa de uma tendência negativa a $5 \%$ de significância.

Nosso resultado vai de encontro ao de Sousa e Serra (2008), os quais encontraram uma tendência negativa a um nível de significância de $10 \%$ para a volatilidade idiossincrática ponderada pelo valor de mercado, tal como feito em nosso estudo, no mercado acionário português. Tais resultados são distintos aos encontrados por Campbell et al. (2001), pois estes últimos estimaram uma tendência positiva e significante a $10 \%$ de significância para $F I R M_{t}$.

Ao diferenciar o comportamento de $F I R M_{t}$ em função da quebra estrutural observa-se que a série teve uma tendência positiva $\mathrm{e}$ significativa ao nível de 5\% no período de janeiro de 1996 a abril de 2000. Por outro lado, é possível rejeitar a hipótese nula para o teste unicaudal à esquerda em favor da hipótese alternativa de presença de uma tendência negativa ao nível de $5 \%$ de significância para o período de maio de 2000 a dezembro de 2010.

Assim, realmente há uma tendência de queda da volatilidade idiossincrática das ações no mercado acionário brasileiro a partir do ponto de quebra. Consequentemente espera-se que haja uma tendência de alta na correlação entre os retornos de ações individuais, uma vez que a parte específica da variância total do retorno de uma ação qualquer tem diminuído.

\footnotetext{
${ }^{10}$ Resultados obtidos utilizando código GAUSS disponibilizado por Timothy J. Vogelsang. 258 Revista Brasileira de Finanças (Online), Rio de Janeiro, Vol. 14, N.2, June $2016 @$
} 
Tabela 8

Resultados empíricos do teste de tendência para as séries de volatilidade e correlação média.

\begin{tabular}{llllll}
\hline Séries & Período & $\tilde{\beta}_{2}$ & $\begin{array}{l}t-P S_{T} \\
10 \%\end{array}$ & $\begin{array}{l}t-P S_{T} \\
5 \%\end{array}$ & $\begin{array}{l}t-P S_{T} \\
1 \%\end{array}$ \\
\hline$M K T_{t}$ & $96-10$ & -0.0003 & -0.6866 & -0.6622 & -0.5825 \\
$I N D_{t}$ & $96-10$ & -0.0002 & -1.0626 & -0.9953 & -0.7897 \\
FIRM $_{t}$ & $96-10$ & -0.0005 & -1.9318 & -1.7409 & -1.2050 \\
FIRM $_{t}$ & $01 / 96-04 / 00$ & 0.0027 & 2.0544 & 1.8591 & 1.3060 \\
FIRM $_{t}$ & $05 / 00-12 / 10$ & -0.0005 & -2.3969 & -2.2579 & -1.8279 \\
CORRVM $_{t}$ & $96-10$ & 0.0003 & 1.4210 & 1.3953 & 1.3081 \\
CORRIP $_{t}$ & $96-10$ & 0.0006 & 3.4342 & 3.3789 & 3.1904 \\
\hline
\end{tabular}

\begin{tabular}{|c|c|c|c|}
\hline \multicolumn{4}{|c|}{ Valores críticos para as estatísticas do teste unicaudal } \\
\hline À esquerda & & & À direita \\
\hline$\%$ & $t-P S_{T}$ & $\%$ & $t-P S_{T}$ \\
\hline 0.90 & $-1.331^{1}$ & 0.90 & 1.331 \\
\hline 0.95 & -1.720 & 0.95 & 1.720 \\
\hline 0.99 & -2.647 & 0.99 & 2.647 \\
\hline
\end{tabular}

Nota: A estatística $t-P S_{T}$ é simétrica ao redor de zero como um teste- $t$ padrão. Desta forma, o teste de hipótese unicaudal à esquerda apresenta valores críticos negativos enquanto que o oposto vale para teste de hipótese unicaudal à direita.

Fonte: os autores.

Tabela 9

Decomposição da média e variância

\begin{tabular}{|c|c|c|c|}
\hline & $M K T_{t}$ & $I N D_{t}$ & $F I R M_{t}$ \\
\hline \multicolumn{4}{|l|}{ Média } \\
\hline $01 / 1996-12 / 2010$ & 0.530 & 0.240 & 0.230 \\
\hline $01 / 1996-12 / 2001$ & 0.388 & 0.228 & 0.383 \\
\hline $01 / 2002-12 / 2010$ & 0.624 & 0.249 & 0.127 \\
\hline \multicolumn{4}{|l|}{ Variância } \\
\hline$M K T_{t}$ & 0.338 & 0.175 & 0.134 \\
\hline$I N D_{t}$ & & 0.052 & 0.082 \\
\hline$F I R M_{t}$ & & & 0.217 \\
\hline
\end{tabular}

Nota: Assim como Campbell et al. (2001) definimos a volatilidade de uma ação qualquer como $\sigma_{r t}^{2}=M K T_{t}+I N D_{t}+F I R M_{t}$. Então, para a média da volatilidade, $1=E\left(M K T_{t}\right) / E\left(\sigma_{r t}^{2}\right)+$ $E\left(I N D_{t}\right) / E\left(\sigma_{r t}^{2}\right)+E\left(F I R M_{t}\right) / E\left(\sigma_{r t}^{2}\right)$.

Para a variância da volatilidade,

$1=\operatorname{Var}\left(M K T_{t}\right) / \operatorname{Var}\left(\sigma_{r t}^{2}\right)+\operatorname{Var}\left(I N D_{t}\right) / \operatorname{Var}\left(\sigma_{r t}^{2}\right)+\operatorname{Var}\left(F I R M_{t}\right) / \operatorname{Var}\left(\sigma_{r t}^{2}\right)+2 \operatorname{Cov}\left(M K T_{t}, I N D_{t}\right) /$

$\operatorname{Var}\left(\sigma_{r t}^{2}\right)+2 \operatorname{Cov}\left(M K T_{t}, I N D_{t}\right) / \operatorname{Var}\left(\sigma_{r t}^{2}\right)+2 \operatorname{Cov}\left(F I R M_{t}, I N D_{t}\right) / \operatorname{Var}\left(\sigma_{r t}^{2}\right)$.

Fonte: os autores. 
Reportamos na tabela 9 a parcela da variância de $M K T_{t}$ na linha $M K T_{t}$ e coluna $M K T_{t}$, a parcela da covariância entre $M K T_{t}$ e $I N D_{t}$ na linha $M K T_{t}$ e coluna $I N D_{t}$, e assim em diante. A tendência linear é retirada de todas as séries antes de fazer o cálculo de decomposição da variância e a tendência não linear é retirada antes de fazer os cálculos de decomposição da média. A tabela 9 mostra quão importante os três componentes são relativos à volatilidade total de uma firma. Primeiro, considere a média. Ao longo de todo o período amostral, a volatilidade do mercado representa cerca de $53 \%$ da média incondicional da volatilidade total, enquanto que $I N D_{t}$ cerca de $12 \%$. Contudo, a menor parcela da volatilidade total é a volatilidade das firmas, com $23 \%$. Consistente com a tendência de queda na volatilidade das firmas, a parte da volatilidade das firmas diminuiu de aproximadamente $38 \%$ no período 01/1996 a 12/2001 para cerca de $13 \%$ no período 01/2002 a 12/2010. A decomposição da variância mostra que a maior parte da variação nas séries temporais é dada pela variação em $M K T_{t}$ e $F I R M_{t}$. Juntos estes dois componentes representam aproximadamente $55 \%$ da variação total na volatilidade das séries temporais. A volatilidade da indústria é mais estável ao longo do tempo.

Em busca de verificar se o comportamento da correlação média entre as ações condiz com a hipótese derivada da conduta apresentada pela volatilidade idiossincrática, estimamos a equação (25) utilizando como peso o valor de mercado das ações $\left(C O R R V M_{t}\right)$ e também adotando uma medida igualmente ponderada $\left(C O R R I P_{t}\right)$, conforme a seção 3.3. A figura 5 apresenta os resultados para as duas medidas de correlação.

Para verificar se a correlação média das ações realmente apresentou uma tendência de alta, novamente utilizamos a abordagem proposta por Vogelsang (1998) realizando um teste unicaudal à direita. A tabela 8 traz os resultados dos testes de tendência para ambas as medidas de correlação $\left(\operatorname{CORRPVM}_{t}, \operatorname{CORRIP}_{t}\right)$ e é possível observar que as duas medidas têm uma tendência de alta e significativa ao nível de significância de $10 \%$ e $1 \%$, respectivamente. 
Figura 5

Correlação média

Painel A: Correlação média das ações ponderadas pelo valor de mercado

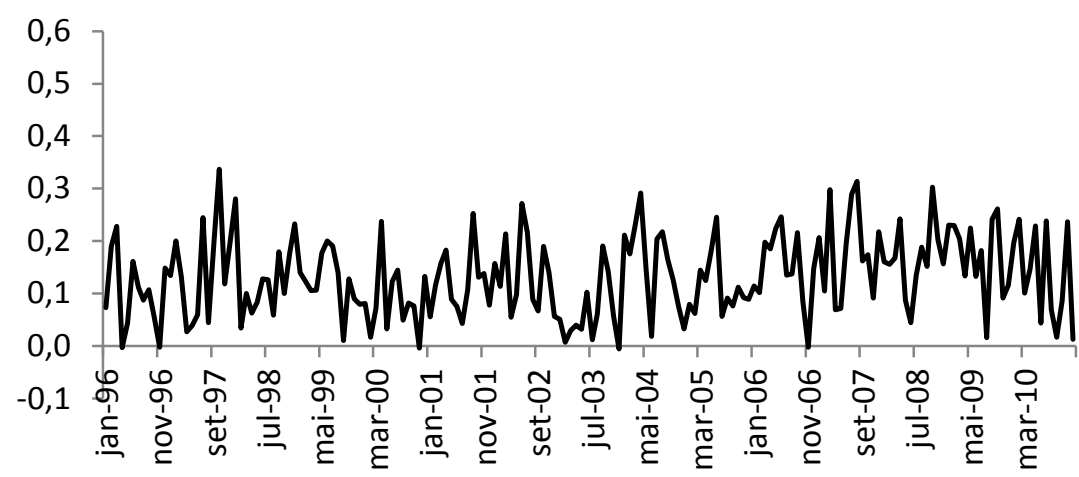

Painel B: Correlação média das ações igualmente ponderadas

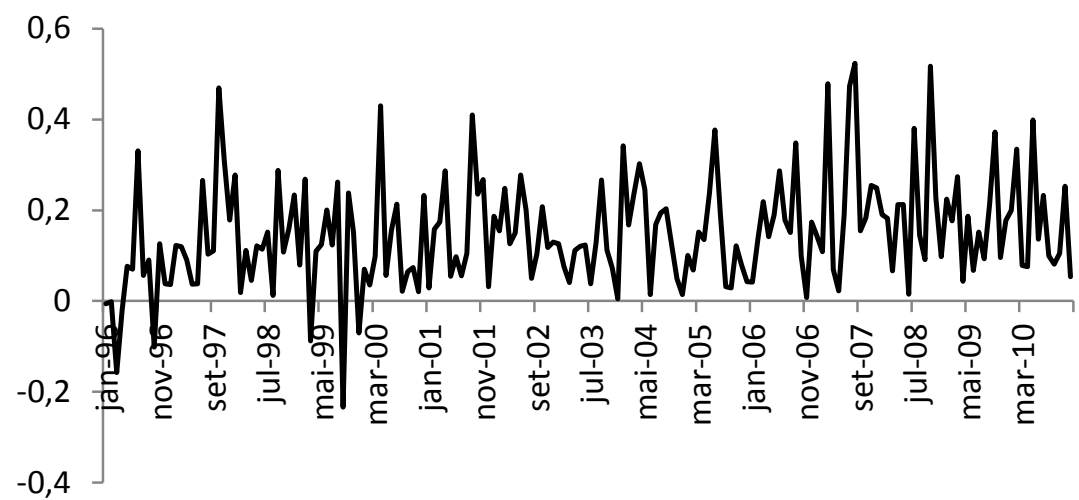

Nota: O painel superior mostra a correlação média obtida através da equação (23) ponderada pelo valor de mercado de cada firma. Por outro lado, o painel inferior apresenta o resultado da correlação média igualmente ponderada.

Portanto, a volatilidade de uma carteira não permanecerá a mesma se houver um aumento da volatilidade específica de cada firma em função da tendência apresentada pela correlação média. Além disso, os benefícios da diversificação caem ao longo do tempo. Um investidor que tem apenas uma ação está sujeito aos riscos integrais desta ação, enquanto que um investidor que tem um número suficiente de ações suporta, praticamente, apenas o risco de mercado. Como a volatilidade idiossincrática tem diminuído relativamente à volatilidade de mercado, a diferença entre esses riscos tem decrescido. 


\section{Conclusões}

Evidências internacionais mostram que a volatilidade idiossincrática dos retornos de ações individuais tem aumentado ao longo do tempo, tanto em termos absolutos quanto em termos relativos à variância do mercado e da indústria. Este efeito tem sido documentado no mercado de ações dos EUA (Campbell et al., 2001; Xu e Malkiel, 2003; Boyer, Mitton e Vorkink, 2010; Brandt et al., 2010), mercados de ações de países desenvolvidos e emergentes (Morck, Yu e Yeung, 2000; Li et al., 2004; Kearney e Potì, 2008). Ainda, pesquisas sugerem que não existe tendência temporal nos EUA e nenhum outro país desenvolvido ou em países emergentes (Angelidus, 2010; Bakaert et al., 2012) ou tendência de queda, como sugere o trabalho de Sousa e Serra (2008) para o mercado acionário português.

Para o caso brasileiro a presente pesquisa mostrou que a volatilidade específica das firmas tem diminuído a partir de maio de 2000, enquanto que as medidas de volatilidade da indústria e mercado não apresentaram nenhuma tendência significativa no período 1996 a 2010. Além disso, a correlação média entre as ações apresentou uma tendência de alta como consequência do comportamento das medidas de volatilidade desagregadas.

Em um primeiro momento e conforme as conclusões de $\mathrm{Xu}$ e Malkiel (2003) espera-se que os custos de transação incorridos pelos investidores tenham diminuído em função da menor quantidade de ações necessárias para diversificar uma carteira de ações.

Nossos resultados vão ao encontro àqueles encontrados por Morck, Yu e Yeung (2000) de que economias com menor PIB per capita têm os preços de suas ações se movendo de maneira mais sincronizada em função do aumento da participação da volatilidade do mercado na volatilidade total das ações. Por outro lado, a maior proteção dos direitos de propriedade em economias com maior PIB per capita é um fator que contribui para a menor sincronia nos preços das ações, segundo Morck, Yu e Yeung (2000).

Um fator que pode ter contribuído para a queda do risco idiossincrático é a criação de segmentos de listagem pela BM\&FBOVESPA e que foram implementados em dezembro de 2000: Novo Mercado, Níveis Diferenciados de Governança Corporativa - Nível 
1 e Nível 2. As companhias são classificadas pela adoção de alguns critérios de governança corporativa diferenciados por cada segmento e que são adotados voluntariamente. Segundo BM\&FBOVESPA (2012), as regras mais rígidas reduzem o risco dos investidores, uma vez que direitos e garantias são assegurados e as informações mais completas são divulgadas reduzindo a assimetria de informações entre controladores, gestores e os participantes do mercado. Consequentemente, a redução do risco contribuirá para uma melhor precificação das ações e fatores específicos não considerados ou até mesmo precificados erroneamente serão mais bem tratados, reduzindo assim, o erro na diversificação do risco idiossincrático.

A participação da variância do mercado e firma na variância total não condicional se mostrou significante indicando que a incerteza sobre essas medidas são importantes componentes da volatilidade total de uma ação qualquer. A volatilidade de mercado parece conduzir as outras medidas de volatilidade enquanto que a volatilidade das firmas não parece ter qualquer efeito sobre a volatilidade da indústria e do mercado.

Estudos futuros podem buscar os determinantes do risco idiossincrático no mercado acionário brasileiro e inferir se o comportamento apresentado por este é característica de tipos especiais de ações, setores ou é comum a todas as ações listadas. Verificar se as conclusões são robustas à utilização de metodologias que permitam obter as medidas de volatilidade e correlação média de forma condicional, pode ser outro objeto de estudo.

\section{Referências}

Akaike, Hirotogu. 1998. Information theory and an extension of the maximum likelihood principle. In: Selected Papers of Hirotugu Akaike. Springer New York, 199-213

Angelidis, Timotheos. 2010. Idiosyncratic risk in emerging markets. Financial Review, 45, n. 4,1053-1078.

Bai, Jushan; \& Perron, Pierre. 1998. Estimating and testing linear models with multiple structural changes. Econometrica, 47-78.

Bai, Jushan; \& Perron, Pierre. 2003. Computation and analysis of multiple structural change models. Journal of applied econometrics, 18, n. 1, 1-22. 
Banz, Rolf W. 1981. The relationship between return and market value of common stocks. Journal of financial economics, 9, n. 1, 3-18.

Basu, Sanjoy. 1977. Investment performance of common stocks in relation to their price-earnings ratios: A test of the efficient market hypothesis. The journal of Finance, 32, n. 3, 663-682.

Bekaert, Geert; \& Wu, Guojun. 2000. Asymmetric volatility and risk in equity markets. Review of Financial Studies, 13, n. 1, 1-42.

Bekaert, Geert; Hodrick, Robert J.; \& Zhang, Xiaoyan. 2012. Aggregate idiosyncratic volatility. Journal of Financial and Quantitative Analysis, 47, n. 06, 1155-1185.

BM\&FBOVESPA. 2012. Segmentos de listagem. Disponível em: http://www.bmfbovespa.com.br/pt_br/produtos/listados-a-vista-ederivativos/renda-variavel/empresas-listadas.htm Acesso em: 22 jun. 2016.

Boyer, Brian; Mitton, Todd; \& Vorkink, Keith. 2010. Expected idiosyncratic skewness. Review of Financial Studies, 23, n. 1, p. 169-202.

Brandt, Michael W. et al. 2010. The idiosyncratic volatility puzzle: Time trend or speculative episodes?. Review of Financial Studies, 23, n. 2, p. 863-899.

Campbell, John Y. et al. 2001. Have individual stocks become more volatile? An empirical exploration of idiosyncratic risk. The Journal of Finance, 56, n. 1, 1-43.

Campbell, John Y. et al. 1997. The econometrics of financial markets. Princeton, NJ: Princeton University Press.

Christiano, Lawrence J. 1992. Searching for a Break in GNP. Journal of Business \& Economic Statistics, 10, n. 3, 237-250.

Dennis, Patrick; \& Strickland, Deon. 2004. The determinants of idiosyncratic volatility. Unpublished working paper, University of Virginia.

Dickey, David A.; \& Fuller, Wayne A. 1981. Likelihood ratio statistics for autoregressive time series with a unit root. Econometrica, 10571072. 
Falkenstein, Eric G. 1996. Preferences for stock characteristics as revealed by mutual fund portfolio holdings. The Journal of Finance, 51, n. 1, 111-135.

Fama, Eugene F.; \& French, Kenneth R. 1992. The cross-section of expected stock returns. The Journal of Finance, 47, n. 2, 427-465.

Fama, Eugene F.; \& French, Kenneth R. 1993. Common risk factors in the returns on stocks and bonds. Journal of financial economics, 33, n. 1, 3-56.

Fama, Eugene F.; \& French, Kenneth R. 1996. Multifactor explanations of asset pricing anomalies. The journal of finance, 51, n. 1, 55-84.

Fomby, Thomas B.; \& Vogelsang, Timothy J. 2002. The application of size-robust trend statistics to global-warming temperature series. Journal of Climate, 15, n. 1, 117-123.

$\mathrm{Fu}$, Fangjian. 2009. Idiosyncratic risk and the cross-section of expected stock returns. Journal of Financial Economics, 91, n. 1, 24-37.

Galdi, Fernando Caio; \& Securato, José Roberto. 2007. O risco idiossincrático é relevante no mercado brasileiro. Revista Brasileira de Finanças, 5, n. 1, 41-58.

Glynn, John; Perera, Nelson; \& Verma, Reetu. 2007. Unit root tests and structural breaks: a survey with applications.

Hamilton, James D. 1989. A new approach to the economic analysis of nonstationary time series and the business cycle. Econometrica, 357384.

Kearney, Colm; \& Potì, Valerio. 2008. Have European stocks become more volatile? An empirical investigation of idiosyncratic and market risk in the euro area. European Financial Management, 14, n. 3, 419-444.

Kwiatkowski, Denis et al. 1992. Testing the null hypothesis of stationarity against the alternative of a unit root: How sure are we that economic time series have a unit root?. Journal of econometrics, 54, n. 1-3, 159-178.

Lakonishok, Josef; \& Shapiro, Alan C. 1986. Systematic risk, total risk and size as determinants of stock market returns. Journal of Banking \& Finance, 10, n. 1, 115-132. 
Lee, Junsoo; \& Strazicich, Mark C. 2001. Break point estimation and spurious rejections with endogenous unit root tests. Oxford Bulletin of Economics and Statistics, 63, n. 5, 535-558.

Lee, Junsoo; \& Strazicich, Mark C. 2003. Minimum Lagrange multiplier unit root test with two structural breaks. Review of Economics and Statistics, 85, n. 4, 1082-1089.

Li, Kan et al. 2004. Firm-specific variation and openness in emerging markets. Review of Economics and Statistics, 86, n. 3, p. 658-669.

Lintner, John. 1965. The valuation of risk assets and the selection of risky investments in stock portfolios and capital budgets. The review of economics and statistics, 13-37.

Lumsdaine, Robin L.; \& Papell, David H. 1997. Multiple trend breaks and the unit-root hypothesis. Review of economics and Statistics, 79, n. 2, 212-218.

Markowitz, Harry. 1952. Portfolio selection. The journal of finance, 7, $\mathrm{n}$. $1,77-91$.

Martin, Diógenes Manoel Leiva; Cia, Josilmar Cordenonssi; \& Kayo, Eduardo Kazuo. 2010. Determinantes do risco idiossincrático no Brasil no período de 1996 a 2009. Anais do Encontro Nacional da Associação Nacional de Pós-Graduação e Pesquisa em Administração (ENANPAD).

De Mendonça, Fernanda Primo et al. 2012. A Relação entre Risco Idiossincrático e Retorno no Mercado Acionário Brasileiro/The Relationship between Idiosyncratic Risk and Returns in the Brazilian Stock Market. Revista Contabilidade \& Finanças, 23, n. 60.

Merton, Robert C. 1980. On estimating the expected return on the market: An exploratory investigation. Journal of financial economics, 8, n. 4, 323-361.

De Morais, Igor A. C.; \& PORTUGAL, Marcelo S. 1999. Modelagem e previsão de volatilidade determinística e estocástica para a série do Ibovespa.

Morck, Randall; Yeung, Bernard; \& Yu, Wayne. 2000. The information content of stock markets: why do emerging markets have synchronous stock price movements?. Journal of financial economics, 58, n. 1, 215-260. 
Mossin, Jan. 1966. Equilibrium in a capital asset market. Econometrica, 768-783.

Newey, Whitney K.; \& West, Kenneth D. 1987. Hypothesis testing with efficient method of moments estimation. International Economic Review, 777-787.

Nunes, Luis C.; Newbold, Paul; \& Kuan, Chung-Ming. 1997. Testing for unit roots with breaks: evidence on the great crash and the unit root hypothesis reconsidered. Oxford Bulletin of Economics and Statistics, 59, n. 4, 435-448.

Ohara, Hidetaka I. 1999. A Unit Root Test With Multiple Trend Breaks: A Theory and an Application to US and Japanese Macroeconomic Time-Series. Japanese Economic Review, 50, n. 3, 266-290.

Park, Joon Y.; \& Choi, Buhmsoo. 1988. A new approach to testing for a unit root.Center for Analytic Economics. Cornell University, Working Paper, 88.

Perron, Pierre. 1989. The great crash, the oil price shock, and the unit root hypothesis. Econometrica, 1361-1401.

Phillips, Peter C. B.; \& Perron, Pierre. 1988. Testing for a unit root in time series regression. Biometrika, 75, n. 2, 335-346.

Pollet, Joshua M.; \& Wilson, Mungo. 2010. Average correlation and stock market returns. Journal of Financial Economics, 96, n. 3, 364380 .

Ricca, Bernardo de Oliveira Guerra. 2010. Apreçamento da assimetria idiossincrática no mercado brasileiro de ações.

Schwarz, Gideon et al. 1978. Estimating the dimension of a model. The annals of statistics, $\mathbf{6}$, n. 2, 461-464.

Sharpe, William F. 1964. Capital asset prices: A theory of market equilibrium under conditions of risk. The journal of finance, 19, n. 3 , 425-442.

Sousa, Sónia R.; \& Serra, Ana Paula. 2008. What drives idiosyncratic volatility over time?. Portuguese Economic Journal, v. 7, n. 3, 155181.

Vogelsang, Timothy J. 1998. Trend function hypothesis testing in the presence of serial correlation. Econometrica, 123-148. 
Xu, Yexiao; \& Exchange, Shanghai Stock. 2003. Diversification in the Chinese stock market. School of Management, Working Paper, The University of Texas at Dallas and Shanghai Stock Exchange.

$\mathrm{Xu}$, Yexiao; \& Malkiel, Burton G. 2003. Investigating the behavior of idiosyncratic volatility. The Journal of Business, 76, n. 4, 613-645.

Zivot, Eric; \& Andrews, Donald W. K. 2012. Further evidence on the great crash, the oil-price shock, and the unit-root hypothesis. Journal of Business \& Economic Statistics. 